\title{
The influence of poly(ester amide) on the structural and functional features of 3D additive manufactured poly(- caprolactone) scaffolds
}

Dol:

10.1016/j.msec.2019.01.063

\section{Document Version}

Accepted author manuscript

Link to publication record in Manchester Research Explorer

Citation for published version (APA):

Gloria, A., Frydman, B., Lamas, M. L., Serra, A. C., Martorelli, M., Coelho, J. F. J., Fonseca, A. C., \& Domingos, M. (2019). The influence of poly(ester amide) on the structural and functional features of 3D additive manufactured poly(-caprolactone) scaffolds. Materials Science and Engineering: C. https://doi.org/10.1016/j.msec.2019.01.063

\section{Published in:}

Materials Science and Engineering: C

\section{Citing this paper}

Please note that where the full-text provided on Manchester Research Explorer is the Author Accepted Manuscript or Proof version this may differ from the final Published version. If citing, it is advised that you check and use the publisher's definitive version.

\section{General rights}

Copyright and moral rights for the publications made accessible in the Research Explorer are retained by the authors and/or other copyright owners and it is a condition of accessing publications that users recognise and abide by the legal requirements associated with these rights.

\section{Takedown policy}

If you believe that this document breaches copyright please refer to the University of Manchester's Takedown Procedures [http://man.ac.uk/04Y6Bo] or contact uml.scholarlycommunications@manchester.ac.uk providing relevant details, so we can investigate your claim.

\section{OPEN ACCESS}


The influence of poly(ester amide) on the structural and functional features of $3 \mathrm{D}$ additive manufactured poly( $\varepsilon$-caprolactone) scaffolds

Antonio Gloria ${ }^{1}$, B. Frydman ${ }^{2}$, Miguel L. Lamas ${ }^{3}$, Armenio C. Serra ${ }^{3}$, Massimo Martorelli ${ }^{4}$, Jorge F.J. Coelho ${ }^{3}$, Ana C. Fonseca ${ }^{3^{*}}$, M. Domingos ${ }^{2^{*}}$

${ }^{1}$ Institute of Polymers, Composites and Biomaterials - National Research Council of Italy, V.le J.F. Kennedy 54 -Mostra d'Oltremare Pad. 20, 80125 Naples, Italy.

${ }^{2}$ School of Mechanical, Aerospace and Civil Engineering, University of Manchester, UK

${ }^{3}$ CEMMPRE, Department of Chemical Engineering, University of Coimbra, Polo II, Pinhal de Marrocos, 3030-790 Coimbra,Portugal

${ }^{4}$ Department of Industrial Engineering, Fraunhofer JL IDEAS - University of Naples Federico II, P.le Tecchio 80, 80125 Naples, Italy.

*Corresponding Author(s): Ana C. Fonseca.Email: ana.clo.fonseca@gmail.com; Marco Domingos. Tel: (+44) 1613064889.Email: marco.domingos@manchester.ac.uk; 


\begin{abstract}
The current research reports for the first time the use of blends of poly( $\varepsilon$-caprolactone) (PCL) and poly(ester amide) (PEA) for the fabrication of 3D additive manufactured scaffolds. Tailor made PEA was synthesized to afford fully miscible blends of PCL and PEA using different percentages (5, 10, 15 and 20\% w/w). Stability, characteristic temperatures and material's compatibility were studied through thermal analyses (i.e., TGA, DSC). Even though DMTA and static compression tests demonstrated the possibility to improve the storage modulus, Young's modulus and maximum stress by increasing the amount of PEA, a decrease of hardness was found beyond a threshold concentration of PEA as the lowest values were achieved for PCL/PEA (20\% w/w) scaffolds (from $0.39 \pm 0.03 \mathrm{GPa}$ to $0.21 \pm 0.02 \mathrm{GPa}$ in the analysed load range).

The scaffolds presented a controlled morphology and a fully interconnected network of internal channels. The water contact angle measurements showed a clear increase of hydrophilicity resulting from the addition of PEA. This result was further corroborated with the improved adhesion and proliferation of human mesenchymal stem cells (hMSCs). The presence of PEA also influenced the cell morphology. Better cell spreading and a much higher and homogenous number of cells were observed for PCL/PEA scaffolds when compared to PCL ones.
\end{abstract}

Key words: Additive manufacturing, Scaffold design, Poly(ester amide), Thermal and Mechanical properties, Image analysis, Biological properties 


\section{Introduction}

Top-down approaches based on the use of scaffolds capable of mimicking the Extracellular Matrix (ECM) environment and providing mechanical support for seeded or recruited cells have proven to be extremely efficient for the regeneration of load bearing tissues, in particular bone and cartilage [1-4]. When combined with appropriate biochemical cues, these 3D porous constructs have the ability to instruct cell migration, proliferation and deposition of newly synthetized ECM [5]. The design of scaffolds is frequently regarded as a challenging task due to the multitude and often antagonistic nature of the biomechanical requirements that they have to display in order to ensure a successful guided-tissue formation. A wide range of natural and synthetic polymers have been proposed to simplify the design of scaffolds for Tissue Engineering (TE), including collagen, chitosan, poly( $\varepsilon$-caprolactone) (PCL), Poly(L-lactic acid) (PLLA), etc.[6-9]. Natural polymers possess an inherent biocompatibility but the time consuming purification processes and the great variability in terms of properties strongly limit their application in TE. Moreover, if proteins are used, problems related with disease transmission and immune rejection can also occur. Synthetic biodegradable polymers, in turn, can be fine-tuned to match the physical, chemical and biological features of the target tissue and degrade at a controlled rate. Furthermore, these materials can be considered for scaffold fabrication using a wide range of conventional (e.g. electrospinning, solvent casting) and advanced manufacturing techniques (e.g. bioprinting). Biodegradable thermoplastics, in particular PCL, have been extensively investigated for different applications in TE [10-12]. Our research group and others have taken advantage of PCL unique properties, namely high solubility, thermal stability, ease of processability and ability to blend with other materials, providing a variety of 3D tissue-analogue constructs[13-15]. However, the use of PCL as a cell-instructive material for tissue regeneration is still hindered by its slow degradation rate (i.e., from six to thirty six months as function of molecular weight), low hydrophilicity and poor bioactivity [16]. To overcome these limitations, a growing interest has been dedicated to poly(ester amide)s (PEAs) in an attempt to develop functional biomaterials with enhanced cell-matrix interactions. PEAs can be classified as a group of biodegradable synthetic polymers, containing both ester and amide linkages along their polymer backbone, thereby allowing them to associate the good biodegradability of polyesters with good thermo-mechanical properties of polyamides[17]. The use of different monomers (e.g. $\alpha$-amino acids, $\alpha$-hydroxy acids, fatty diacids, diols, etc.) in the co-polymerization process allows for the generation of PEAs with tunable properties. Although synthetic monomers have been extensively investigated, there is an upward interest on the incorporation of $\alpha$-amino acids as a way to yield PEA with improved biological performance (e.g. enzymatic degradation and cell-matrix interactions) and flexible functionalization (e.g. of pendant functional groups) [18]. The 
synthesis of PEAs based on $\alpha$-amino acids can be performed via melt, solution or interfacial polycondensation techniques with their intrinsic advantages and limitations well reported in the literature [17]. Our research team has recently reported a cost-effective method for the synthesis of novel PEAs containing both $\alpha$-amino acids (glycine, L-phenylalanine) and $\alpha$-hydroxy acids (Llactic acid)[19,20]. It has been demonstrated how the properties of the obtained materials, in particular mechanical, thermal, enzymatic degradation and biological interaction with cells, can be modulated by the incorporation of different pendent functional groups. Also, Knight et al., (2014) has employed interfacial polycondensation to synthetize PEAs based on L-phenylalanine and Laspartic acid for vascular TE applications. The authors have shown the ability of the material to form electrospun meshes with uniform fibres capable of supporting the adhesion, proliferation and phenotype expression of human coronary artery smooth muscle cells (hCASMCs). The potential of PEAs for electrospinning has been further demonstrated with the development of synthetic elastomeric scaffolds with tunable mechanical and physical properties [22]. Despite all the advantages in using PEAs for biomedical applications, especially for soft tissue engineering, the processing methods employed to create artificial 3D PEA-based ECMs are still limited to electrospinning, freeze-drying, solvent casting and microfabrication [23-25].

The current research reports for the first time a strategy to use blends of $\alpha$-amino acids-based PEA and PCL to generate 3D bioprinted scaffolds using tailor made PEA. A first study of the influence of poly(ester amide) on the structural and functional features of $3 \mathrm{D}$ additive manufactured poly $(\varepsilon-$ caprolactone) scaffolds was performed using water contact angle measurements, morphological, thermal, mechanical and biological analyses.

\section{Materials and Methods}

\subsection{Materials}

Poly( $\varepsilon$-caprolactone) (PCL, CAPA 6500, $\mathrm{Mw}=50,000)$ in the form of $3 \mathrm{~mm}$ pellets was obtained from Perstorp Caprolactones (Cheshire, UK) and used as received for the production of the scaffold. Diethylene glycol (DEG) (99 \%), p-toluenesulfonic acid monohydrate ( $p$-TSA), glycine (>99\%), anhydrous sodium carbonate $\left(\mathrm{Na}_{2} \mathrm{CO}_{3}\right)$ were purchased from Sigma-Aldrich (St Louis, USA), and used as received. Sebacoyl chloride (92 \%) was purchased from TCI Europe (Zwijndrecht, Belgium). Dichloromethane $\left(\mathrm{CH}_{2} \mathrm{Cl}_{2}\right)$, isopropanol, and toluene were supplied by José Manuel Gomes dos Santos Lda (Odivelas, Portugal) and used as received. Deuterated dimethylsulfoxide (DMSO- $d_{6}$ ) was purchased from Eurisotop (St Aubain, France). 


\subsection{Synthesis of poly(ester amide) (PEA)}

\subsubsection{Synthesis of the bis( $\alpha$-amino acid) ester}

A suspension of glycine (55 mmol), DEG (25 mmol) and p-TSA (60 mmol) in toluene (Figure 1) was heated up to $150{ }^{\circ} \mathrm{C}$ under stirring, in a round bottom flask equipped with a Dean-Stark apparatus and a condenser with a drying tube. The suspension was kept under reflux until no more water was distilled. The excess of toluene was removed under vacuum and the resulting material was recrystallized from an isopropanol/ethyl acetate mixture $(80 / 20, v / v)$ [26,27]. The ${ }^{1} \mathrm{H}$ NMR spectrum of the glycine based bis( $\alpha$-amino acid) ester is presented in Figure S1.

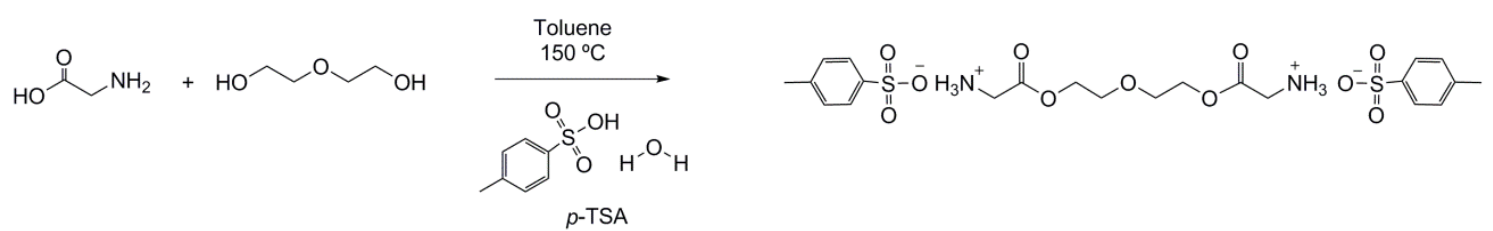

Figure 1. Synthesis of the bis( $\alpha$-amino acid) ester.

${ }^{1} \mathrm{H}$ NMR (600 MHz, DMSO- $d_{6}$ ): $\delta=7.49-7.13\left(\mathrm{~d}, \mathrm{H}^{8}, \mathrm{Ar}-\mathrm{H}\right), 4.28\left(\mathrm{t}, \mathrm{H}^{4}, \mathrm{COOCH}_{2} \mathrm{CH}_{2}\right.$ ), 3.85 (s, $\left.\mathrm{H}^{4}, \mathrm{NH}_{3}{ }^{+} \mathrm{CH}_{2}\right), 3.68\left(\mathrm{t}, \mathrm{H}^{4}, \mathrm{COOCH}_{2} \mathrm{CH}_{2}\right), 2.29\left(\mathrm{~s}, \mathrm{H}^{6}, \mathrm{Ar}-\mathrm{CH}_{3}\right)$.

\subsubsection{Synthesis of PEA}

The PEA was prepared by interfacial polycondensation as previously described by our group [20]. Briefly, the bis $\left(\alpha\right.$-amino acid) ester $(18 \mathrm{mmol})$ was dissolved in distilled water $(60 \mathrm{~mL}) . \mathrm{Na}_{2} \mathrm{CO}_{3}$ (36 mmol) was added and the resulting solution was placed in an ice bath. Then, sebacoyl chloride (18 mmol) dissolved in $\mathrm{CH}_{2} \mathrm{Cl}_{2}(60 \mathrm{~mL})$ was added dropwise to the aqueous solution under mechanical stirring. The reaction was allowed to proceed during $5 \mathrm{~h}$ (Figure 2). The precipitated polymer was recovered by filtration, washed thoroughly with distilled water and dried under vacuum, at $40{ }^{\circ} \mathrm{C}[26,27]$. The ${ }^{1} \mathrm{H}$ NMR spectrum of the glycine based PEA is presented in Figure S1.

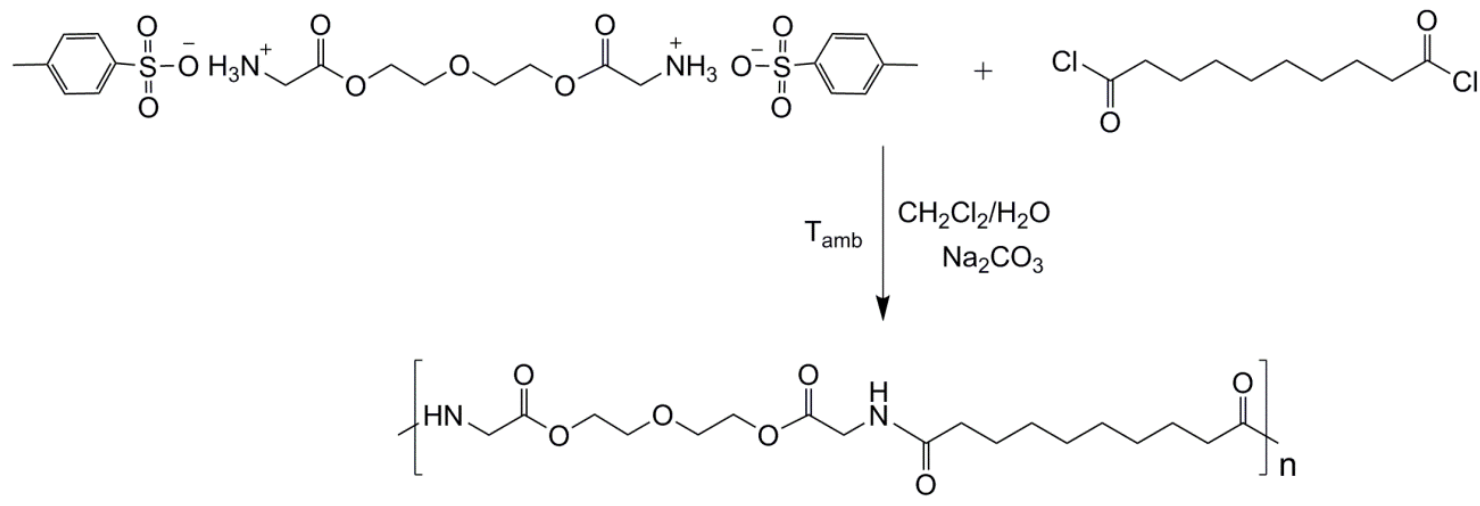

Figure 2. Synthesis of the PEA. 


\subsection{Preparation of PCL/PEA blends}

PCL/PEA systems were prepared by melt blending in order to avoid the use organic solvents aiming a future scalability of the process. Briefly, PCL pellets were melted using a commercial microcompounder (HAAKE Standard MiniLab 3 Micro Compounder, Thermo Fisher Scientific, Italy) at $100^{\circ} \mathrm{C}$ and $40 \mathrm{rpm} / \mathrm{min}$, during $10 \mathrm{~min}$. Afterwards, the PEAs were added to the molten PCL at different percentages (5\%, 10\%, 15\% and 20\% w/w) and kept in the mixer for 40 minutes at $180^{\circ} \mathrm{C}$ and $40 \mathrm{r} / \mathrm{min}$ to achieve complete homogenization. Obtained blends were then removed from the mixer and allowed to solidify at room temperature for 2 hours. PCL/PEA systems were then cut into smaller pellets and kept under controlled environment for further processing and characterization. This procedure was adopted for the production of all blends regardless the percentage of PEA.

\subsection{Scaffolds design and fabrication}

The production of PCL and PCL/PEA scaffolds was performed using a commercial extrusion-based bioprinter called 3D Discovery (regenHU, Switzerland). The system consists of a screw-driven printing head and a compressed air system that guarantees the continuous feeding of material from the material chamber to the nozzle. Based on previous work from our group [28-31], rectangular prisms measuring $30 \mathrm{~mm}$ (length) x $30 \mathrm{~mm}$ (width) x $6 \mathrm{~mm}$ (height) were designed using BioCAD software (regenHU, Switzerland) and printed with optimized parameters (Table 1) using a $330 \mu \mathrm{m}$ nozzle (RW), 0/90 deposition angle, $270 \mu \mathrm{m}$ layer gap (LG) and $680 \mu \mathrm{m}$ of distance between the filaments (FD) (Figure 3). The obtained rectangular scaffolds with a fully interconnected network of square internal channels were then cut into smaller specimens for further analyses.
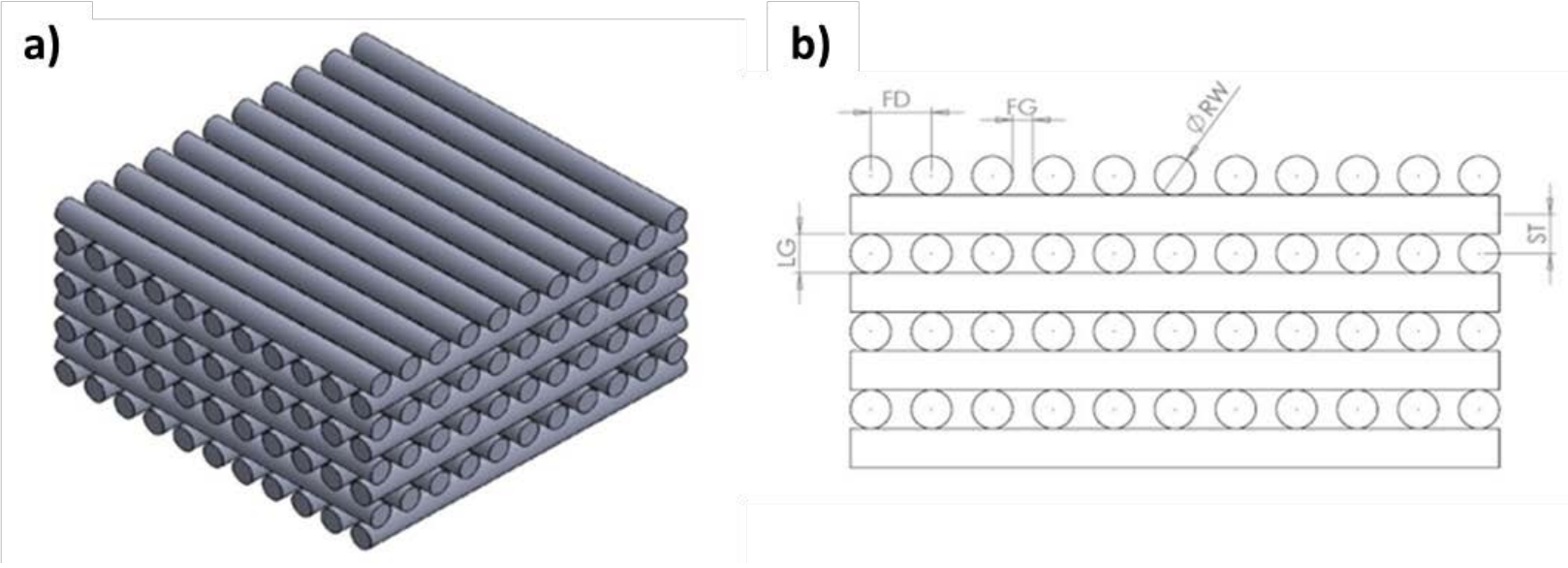

Figure 3. Schematic representation of the scaffold with $0 / 90^{\circ}$ deposition angle. a) 3D CAD model. b) Side view showing the Road Width (RW), Filament Distance (FD), Filament Gap (FG) Layer Gap (LG) and the Slice Thickness (ST). 
Table 1. Process parameters employed in the production of scaffolds using the 3D Discovery. Parameters are denoted as Deposition Velocity (DV), Slice Thickness (ST), Liquefier Temperature (LT), Extrusion Pressure (EP) and Screw Rotation Velocity (SRV).

\section{Process Parameters}

$\begin{array}{ccccc}\text { DV }(\mathbf{m m} / \mathbf{s}) & \text { ST }(\boldsymbol{\mu m}) & \text { LT }\left({ }^{\mathbf{0}} \mathbf{C}\right) & \text { EP (bar) } & \text { SRV (rpm) } \\ 20 & 270 & 90 & 5 & 22\end{array}$

\subsection{Characterization of PEA and scaffolds}

\subsubsection{Chemical structure of the bis( $\alpha$-amino acid) ester and PEA}

Proton Nuclear magnetic resonance $\left({ }^{1} \mathrm{H}\right.$ NMR) spectra of the bis( $\alpha$-amino acid) ester and PEA were obtained in DMSO- $d_{6}$, at $25^{\circ} \mathrm{C}$, on a Varian Unity $600 \mathrm{MHz}$ Spectrometer using a $3 \mathrm{~mm}$ broadband NMR probe. Tetramethylsilane (TMS) was used as internal standard.

\subsubsection{Molecular Weight Distribution}

The molecular weight distribution of the PEAs was determined using an HPSEC Viscotek (Dual detector 270, Viscotek, Houston, TX, USA) with a differential viscosimeter detector and refractive index detector (Knauer K-2301). The column set consisted of a PL $10 \mu \mathrm{m}$ guard

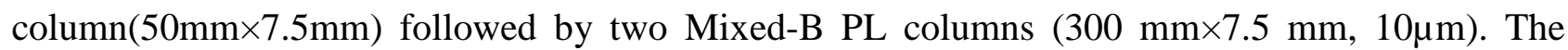
HPLC pump (Knauer K-1001) was set with a flow rate of $1 \mathrm{~mL} \mathrm{~min}^{-1}$. The system was also equipped with a Knauer on-line degasser. The tests were done at $60{ }^{\circ} \mathrm{C}$ using an Elder $\mathrm{CH}-150$ heater. $N, N^{\prime}$-dimethylformamide with $\mathrm{LiBr}(0.03 \% \mathrm{w} / \mathrm{w})$ was used as the eluent. Universal calibration was done with four narrow polystyrene standards $\left(M \mathrm{p}\left(\mathrm{g} \cdot \mathrm{mol}^{-1}\right)=1820,4290,10050\right.$, 30300).

\subsubsection{Scanning Electron Microscopy (SEM)}

Morphological analysis of 3D printed PCL and PCL/PEA scaffolds was carried out using a scanning electron microscope (SEM, FEI Quanta 200). Top and cross-section micrographs were obtained under high vacuum conditions, voltage of $20.0 \mathrm{kV}$ and pressure of $3.2 \times 10^{-5}$ Torr. ImageJ software (National Institute of Health, U.S.A) was subsequently used to evaluate the structural integrity of the scaffolds, pore spatial distribution and consistency between theoretical (pre-defined in the BioCAD) and experimental values of RW and FG. 


\subsubsection{Thermal analysis}

Thermogravimetric analysis (TGA)

The thermal stability of the printed samples was investigated using a TA Instruments Q500 thermogravimetric analyzer (thermobalance sensitivity: $0.1 \mu \mathrm{g}$ ). The temperature calibration was performed in the range of 25 to $1000^{\circ} \mathrm{C}$ by measuring the Curie point of nickel standard, and using open platinum crucibles and a dry $\mathrm{N}_{2}$ purge flow of $100 \mathrm{~mL} / \mathrm{min}$. The analysis was carried out from $25^{\circ} \mathrm{C}$ to $600{ }^{\circ} \mathrm{C}$, at a heating rate of $10^{\circ} \mathrm{C} / \mathrm{min}$, under nitrogen atmosphere.

Differential Scanning Calorimetry (DSC)

The thermal behaviour of the printed samples was further studied by DSC using a TA Instruments Q100 model equipped with a RCS90 cooling unit. The heat flow and the heat capacity were calibrated at $10{ }^{\circ} \mathrm{C} / \mathrm{min}$ using, respectively, indium and sapphire standards. The samples were analysed in aluminium pans with an ordinary aluminium lid. Sample weights ranging from 5 to 10 mg were used. A dry nitrogen purge flow of $50 \mathrm{mLmin}^{-1}$ was used in all measurements. The samples were heated at $10{ }^{\circ} \mathrm{C} / \mathrm{min}$ from -80 to $300{ }^{\circ} \mathrm{C}$, after performing a cycle in which the samples were heated from $25{ }^{\circ} \mathrm{C}$ to $300{ }^{\circ} \mathrm{C}$ and cooled to $-80{ }^{\circ} \mathrm{C}$ to erase the samples' thermal history.

The percentage of crystallinity of the PCL phase in the scaffold was determined using the following equation:

$X_{C}=\frac{\Delta H_{\text {exp }}}{w_{P C L} \Delta H_{u}^{0}} \times 100$

Where $X_{C}$ is the \% of crystallinity, $\Delta H_{\text {exp }}$ is the experimental enthalpy of melting, $\Delta H_{u}^{0}$ is the enthalpy of $100 \%$ crystalline PCL $\left(\Delta H_{u}^{0}=139.5 \mathrm{~J} / g\right)$ [32] and $w_{P C L}$ is the weight fraction of PCL in the scaffold.

\subsubsection{Mechanical analysis}

\section{Dynamic Mechanical Thermal Analysis (DMTA)}

Dynamic Mechanical Thermal Analysis (DMTA) was performed on samples with dimensions 5.0 $\mathrm{mm}(\mathrm{l}) \times 5.0 \mathrm{~mm}(\mathrm{w}) \times 0.5 \mathrm{~mm}\left(\mathrm{~h}_{0}\right)$. The samples were analysed in dual cantilever bending mode using a Tritec 2000 DMA (Triton Technology Ltd, Portugal). The tests were carried out from $-100{ }^{\circ} \mathrm{C}$ to $50{ }^{\circ} \mathrm{C}$, in multi frequency mode $(1,2,5,10 \mathrm{~Hz})$, with a heating rate of $2{ }^{\circ} \mathrm{C} / \mathrm{min}$. The $T_{\mathrm{g}}$ of the samples was determined from the maximum of the tan $\delta$ curve, at $1 \mathrm{~Hz}$. 


\section{Nanoindentation tests}

Nanoindentation tests were performed on the fibres of PCL and PCL/PEA scaffolds. All the measurements were carried out in $1 \mathrm{mN}$ to $5 \mathrm{mN}$ load range using a Nanotest Platform (Micromaterials, U.K.) with a diamond pyramid-shaped Berkovich-type indenter tip.

Trapezoidal load functions were imposed considering a load hold period of $20 \mathrm{~s}$ and a loadingunloading rate of $300 \mu \mathrm{N} / \mathrm{s}$. Load-depth curves were obtained and hardness values were evaluated taking into account the Oliver and Pharr method [33]. In particular, hardness $(\mathrm{H})$ was determined according to the following equation:

$H=\frac{P_{\max }}{A_{c}}$

where $P_{\max }$ is the applied peak load and $A_{c}$ represents the projected contact area at the specified load. The projected contact area $A_{c}$ depends on the geometry of the tip and it is determined from the penetration depth.

Compression tests

Compression tests were carried out on PCL and PCL/PEA block-shaped scaffolds which were characterized by a length (l) of $5.0 \mathrm{~mm}$, a width (w) of $5.0 \mathrm{~mm}$ and a height (h0) of $6.0 \mathrm{~mm}$. All the tests were performed at a rate of $1 \mathrm{~mm} / \mathrm{min}$ up to a strain of $0.4 \mathrm{~mm} / \mathrm{mm}$, using an INSTRON 5566 testing system. The procedure used to evaluate the "apparent” stress and strain was described in a previous work [34]. The compressive modulus was evaluated from the slope of the initial linear region of the stress-strain curve.

\subsubsection{Water contact angle measurements}

Water contact angle measurements were performed on the fibres of PCL and PCL/PEA scaffolds using a DATAPHYSICS OCA 20 apparatus. Distilled water was dropped on single fibres in different sites and the contact angle was evaluated. Specifically, CCD cameras recorded the process of the droplet dropping on the fibre. The baseline for a sessile drop contact angle was made at the liquid-solid interphase. Contact angles were evaluated using the ellipse method for the extraction of the drop profile, as described in the literature [35,36], and reported as mean value \pm standard deviation.

\subsubsection{Biological analysis}

3D printed PCL and PCL/PEA scaffolds were fitted inside 12 well cell culture plates and prepared for cell seeding by first soaking in $70 \%$ ethanol, then in $1 \%$ antibiotic/antimycotic in phosphatebuffered saline (PBS) and pre-wetted in medium (2 h). All the scaffolds were then seeded with bone marrow-derived human mesenchymal stem cells (hMSCs) (Lonza, MD), which were used at 
passages 4-6 from primary culture, using a density of $1 \times 10^{4}$ cells/sample. PCL scaffolds without hMSCs were also treated in the same conditions and used as negative controls. As reported in previous works [37,38], cell viability and proliferation were evaluated by using the Alamar Blue assay (AbD Serotec Ltd, UK). The optical density was measured with a spectrophotometer (Sunrise; Tecan, Männedorf, Zurich, Switzerland) at wavelengths of 570 and $595 \mathrm{~nm}$. Each experiment was performed at least three times in triplicate. To qualitatively determine cell adhesion and spreading at 1, 3 and 7 days after seeding, cell-scaffold constructs were also imaged with a confocal laser scanning microscope (CLSM, Zeiss LSM 510/ConfoCor 2) and rhodamine phalloidin staining was used to visualize actin filaments. The confocal images of the cell-scaffold constructs were further analysed with Image $\mathrm{J}$ software to assess the cell morphology using a shape factor as defined in a previous work $[1,34,39]$. The shape factor was expressed as follows:

$$
\Phi=\frac{\Theta A}{P^{2}}
$$

where $\Theta$ represents a geometric constant $(4 \pi)$ related with the footprint area and $\mathrm{P}$ is the perimeter of a cell. Considering that circular objects have the greatest area-to-perimeter ratio, a shape factor of 1 represents a perfect circle. Conversely, a thin thread-like object would possess the lowest shape factor approaching zero

\subsection{Statistical Analysis}

Statistical analyses were performed using ANOVA followed by Bonferroni post-hoc tests, statistical differences were set at $\mathrm{p}<0.05$.

\section{Results and discussion}

Blends of PCL and PEA with different compositions were prepared to evaluate the effect of the PEA on the properties of the scaffolds. The PEA was prepared from glycine, diethylene glycol and sebacoyl chloride, leading to polymeric structures without pendent side chains, as a route to avoid possible immiscibility issues with PCL. The PEA presents a molecular weight of $c a .7400 \mathrm{~g} / \mathrm{mol}$ $\left(M_{\mathrm{p}}\right)$, with a $Đ$ of 2.5 .

\subsection{Scanning Electron Microscopy (SEM)}

Scanning electron micrographs of 3D printed PCL and PCL/PEA (5\%, 10\%, 15\% and 20\% w/w of PEA) scaffolds allow to confirm the generation of constructs with well-defined square pores of regular dimensions ( $330 \mu \mathrm{m}$ x $330 \mu \mathrm{m}$ ) and uniform distribution (Figure 4). The extruded filaments present a consistent circular geometry with $~ 355 \mu \mathrm{m}$ in diameter according to the nozzle tip used $(330 \mu \mathrm{m})$ and good adhesion between adjacent layers. 

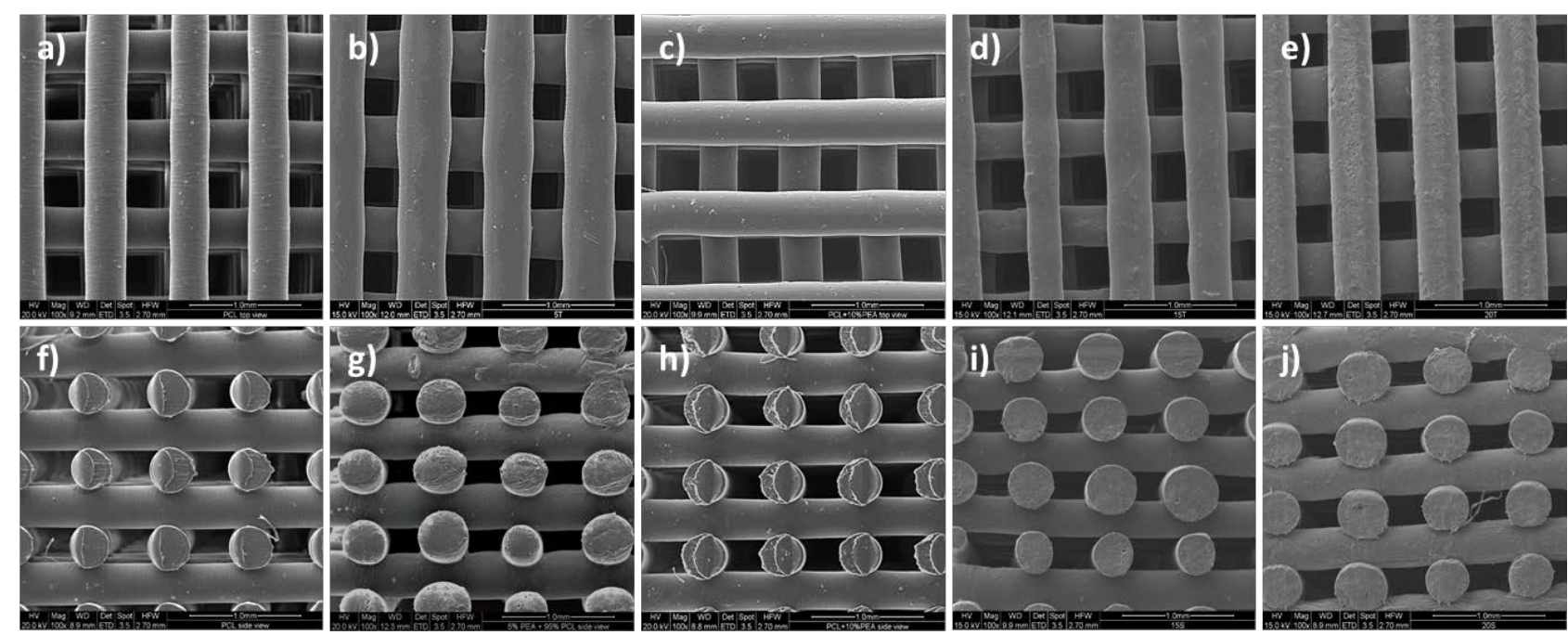

Figure 4. SEM micrographs of 3D printed scaffolds. PCL top (a) and cross-section (f) views; PCL/PEA (5\% w/w) top (b) and cross-section (g) views; PCL/PEA (10\% w/w) top (c) and crosssection (h) views; PCL/PEA (15\% w/w) top (d) and cross-section (i) views; PCL/PEA (20\% w/w) top (e) and cross-section (j) views. Scale bar $=1 \mathrm{~mm}$.

SEM analysis demonstrated the successful production of PCL and PCL/PEA scaffolds characterised by a fully interconnected network of internal channels. In addition, the characteristics of the 3D printed scaffolds were also evaluated from SEM micrographs and reported in Table 2.

Table 2. Characteristics of 3D printed scaffolds obtained from SEM images: Layer Gap (LG), Road Width (RW) and Filament Gap (FG).

\begin{tabular}{cccc}
\hline Scaffold material & LG $(\boldsymbol{\mu m})$ & $\mathbf{R W}(\boldsymbol{\mu m})$ & FG $(\boldsymbol{\mu m})$ \\
\hline PCL & $289 \pm 10$ & $352 \pm 10$ & $323 \pm 8$ \\
PCL/PEA (5\% w/w) & $240 \pm 9$ & $354 \pm 4$ & $340 \pm 7$ \\
PCL/PEA (10\% w/w) & $280 \pm 9$ & $362 \pm 4$ & $321 \pm 8$ \\
PCL/PEA (15\% w/w) & $280 \pm 8$ & $363 \pm 7$ & $357 \pm 9$ \\
PCL/PEA (20\% w/w) & $272 \pm 13$ & $359 \pm 9$ & $326 \pm 14$ \\
\hline
\end{tabular}


The observed deviations between theoretical and experimental values of RW and FG can be considered marginal ( $\sim 5 \%)$ and are correlated with a die swelling mechanism typical of extruded polymers. Because, these variations are consistent and similar across the different groups of scaffolds the outcome of the different biomechanical tests should not be affected.

\subsection{Thermal analysis}

Thermogravimetric analysis (TGA)

The thermal stability of the scaffolds was evaluated by TGA, in $\mathrm{N}_{2}$ atmosphere, from $25^{\circ} \mathrm{C}$ to 600 ${ }^{\circ} \mathrm{C}$. Figure 5 presents the weight loss profiles of the scaffolds.

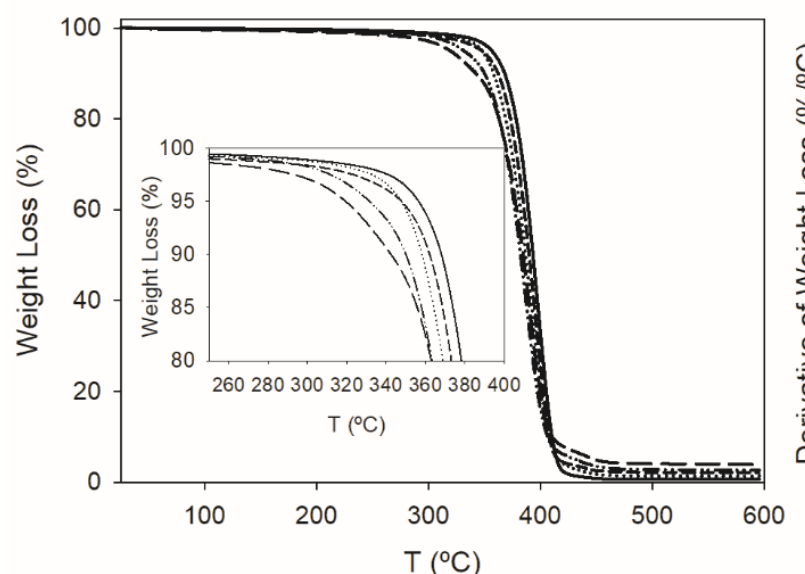

a)

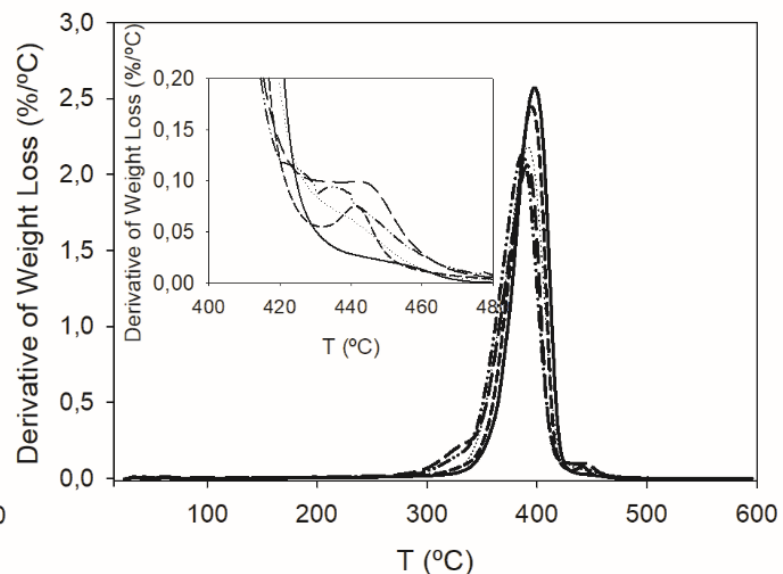

b)

$$
\begin{aligned}
& \begin{array}{ll}
\hline \ldots . . . . . . . . . & \text { PCL } \\
\hline
\end{array} \\
& \text {--_-- PCL/PEA }(10 \% \mathrm{w} / \mathrm{w}) \\
& \text {-...... PCL/PEA (15\% w/w) } \\
& \text { - - - PCL/PEA (20\% w/w) }
\end{aligned}
$$

Figure 5. TG (a) and DTG (b) curves of the PCL/PEA scaffolds.

PCL scaffold showed a single stage of weight loss, whereas the scaffolds containing PEA presented additional stages, being those more evident for PEA weight percentages higher than 10\% w/w (Figure 5B). These additional weight loss stages appeared at temperatures consistent with the degradation temperatures of the PEA (Figure S2 for the TG and DTG curve of PEA). Higher amounts of char residue (Table 3) were found in the scaffolds containing PEA. This non-volatile char residue can be tentatively assigned to the occurrence of crosslinking and/or cyclization reactions during the thermal degradation of the PEA part [40].Both observations may be considered as a clear indication of the presence of the PEA within the scaffold. The scaffolds showed a thermal stability (Table 3 for $T_{5 \%}$ and $T_{10 \%}$ ) in between of that of PCL and neat PEA. 
Table 3. Temperatures of interest taken from the TGA: $\mathrm{T}_{5 \%}$ : temperature corresponding to $5 \%$ of mass loss; $\mathrm{T}_{10 \%}$ : temperature corresponding to $10 \%$ of mass loss (TGA); $\mathrm{T}_{\mathrm{p}}$ :peak temperature (DTG).

\begin{tabular}{ccccc}
\hline Scaffold material & $\boldsymbol{T}_{\mathbf{5 \%}}\left({ }^{\mathbf{0}} \mathbf{C}\right)$ & $\mathbf{T}_{\mathbf{1 0} \%}\left({ }^{\mathbf{0}} \mathbf{C}\right)$ & $\mathbf{T}_{\mathbf{p}}\left({ }^{\mathbf{0}} \mathbf{C}\right)$ & Char Residue (\%) \\
\hline PCL & 356 & 368 & 398 & 0.5 \\
PCL/PEA (5\% w/w) & 347 & 358 & $392 ; 444$ & 1 \\
PCL/PEA (10\% w/w) & 347 & 362 & $395 ; 441$ & 2 \\
PCL/PEA (15\% w/w) & 330 & 350 & $387 ; 437(322(\mathrm{sh}))$ & 3 \\
PCL/PEA (20\% w/w) & 318 & 342 & $391 ; 445(324(\mathrm{sh}))$ & 4 \\
\hline PEA & $\left({ }^{*}\right)$ \\
\hline
\end{tabular}

${ }^{(*)}$ Unprocessed PEA, (sh) shoulder

Table 3 shows that the inclusion of the PEAs in the formulation led to a decrease in the thermal stability, most probably due the lower thermal stability of the PEA when compared with PCL. The highest decrease in the $T_{5 \%}$ and $T_{10 \%}$ is observed for the samples with $15 \% \mathrm{w} / \mathrm{w}$ and $20 \% \mathrm{w} / \mathrm{w}$ of PEA. Thus, these results suggest that there is an optimum amount of PEA to be added, in order to have the samples with a thermal stability closer to PCL. Nevertheless, it should be stressed that at the temperature at which the scaffolds will be used (ca. $37^{\circ} \mathrm{C}$ ), the weight loss is negligible. Regarding the $T_{\mathrm{p}}$ values, the 7 can be tentatively ascribed to interactions that could occur between the components within the sample, that make the rate of weight loss to attain its maximum at lower or higher temperatures.

\section{Differential scanning calorimetry (DSC)}

The thermal behaviour of the scaffolds below degradation temperature was studied by DSC. Figure 6 presents the heat flow curves for the cooling cycle and the second heating cycle for each scaffold. The heat flow curve for the second heating cycle of the PEA is shown in supporting information (Figure S3). 


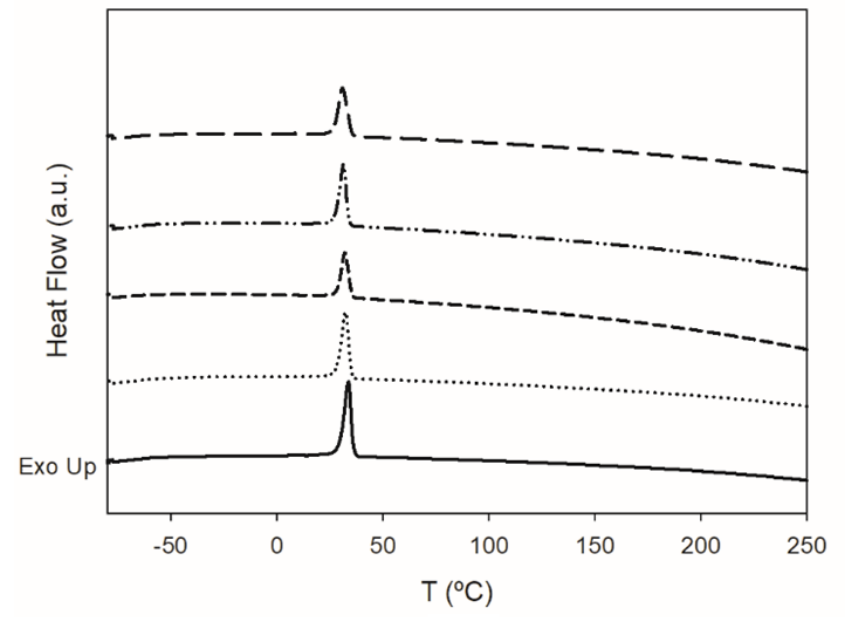

a)

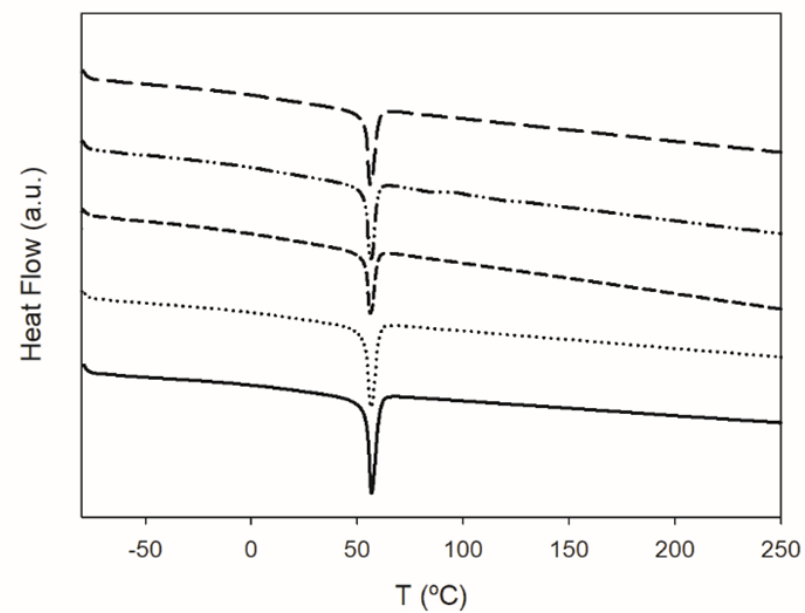

b)

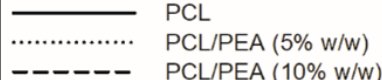

$$
\begin{aligned}
& -\cdots-\cdots-\cdots \quad \text { PCL/PEA (15\% w/w) } \\
& \text { - - - PCL/PEA }(20 \% \mathrm{w} / \mathrm{w})
\end{aligned}
$$

Figure 6. Heat flow curves of the scaffolds (a) cooling cycle, and (b) $2^{\text {nd }}$ heating cycle.

From DSC analysis, it was possible to observe a well-defined exothermic peak in the cooling cycle (Figure 6A), corresponding to the crystallization of the samples. In the subsequent heating cycle (Figure 6B), a single endothermic peak, ascribed to the melting of the scaffolds was evident. The range of temperatures in which such peaks appear are near of those reported for PCL $\left(T_{\mathrm{C}} \sim 33{ }^{\circ} \mathrm{C}\right.$, $\left.T_{\mathrm{m}} \sim 56{ }^{\circ} \mathrm{C}\right)[41,42]$. The absence of any peak corresponding to the crystallization or melting of the PEA ( $T_{\mathrm{m}} \sim 130{ }^{\circ} \mathrm{C}, T_{\mathrm{cc}} \sim 87{ }^{\circ} \mathrm{C}$, see Figure S3 for the heat flow curve of the PEA), suggest that the PCL and PEA are compatible materials for the selected range of weight percentages. Table 4 summarizes the relevant data taken from the DSC analysis.

Table 4. Relevant data taken from the heat flow curves of the scaffolds.

\begin{tabular}{ccccc}
\hline Scaffold material & $\boldsymbol{T}_{\mathbf{m}}\left({ }^{(} \mathbf{C}\right)$ & $\boldsymbol{T}_{\mathbf{c}}\left({ }^{\mathbf{O}} \mathbf{C}\right)$ & $\boldsymbol{\Delta H}_{\mathbf{m}}\left(\mathbf{J ~ g ~}^{-1}\right)$ & $\boldsymbol{X}_{\mathbf{c}}(\mathbf{\%})$ \\
\hline PCL & 56.8 & 33.7 & 55.0 & 39.4 \\
PCL/PEA (5\% w/w) & 56.4 & 32.3 & 60.3 & 45.5 \\
PCL/PEA (10\% w/w) & 56.2 & 32.1 & 55.4 & 44.1 \\
PCL/PEA (15\% w/w) & 56.4 & 31.4 & 56.3 & 47.5 \\
PCL/PEA (20\% w/w) & 56.1 & 30.9 & 53.0 & 47.5 \\
\hline
\end{tabular}

The $T_{\mathrm{m}}$ of the scaffolds did not suffer any change by increasing the amount of PEA. In turn, the $T_{\mathrm{c}}$ decreases, for increasing amounts of PEA, being the highest decrease observed for the scaffold containing $20 \% \mathrm{w} / \mathrm{w}$ of PEA. Regarding the percentage of crystallinity $\left(X_{\mathrm{c}}\right)$ of the PCL phase in the 
scaffold, an augment was observed for increasing amounts of PEA. The results suggest that the inclusion of the PEA favours the crystallization of PCL in the samples [43], which might result in scaffolds with enhanced mechanical properties.

\subsection{Mechanical analysis}

\section{Dynamic Mechanical Thermal Analysis (DMTA)}

The thermomechanical properties of the scaffolds were analysed by DMTA. The measurements were carried out in a $-100{ }^{\circ} \mathrm{C}$ to $50{ }^{\circ} \mathrm{C}$ temperature range, in multifrequency mode, using a heating rate of $2{ }^{\circ} \mathrm{C} \cdot \mathrm{min}^{-1}$. Figure 7 reports the tan $\delta$ trace of the scaffolds at the frequency of $1 \mathrm{~Hz}$. The $T_{\mathrm{g}}$ of the samples was determined from the maximum of $\tan \delta$, at $1 \mathrm{~Hz}$ [47]. The $\tan \delta$ traces of the scaffolds in multifrequency mode are presented in supporting information (Figure S4).

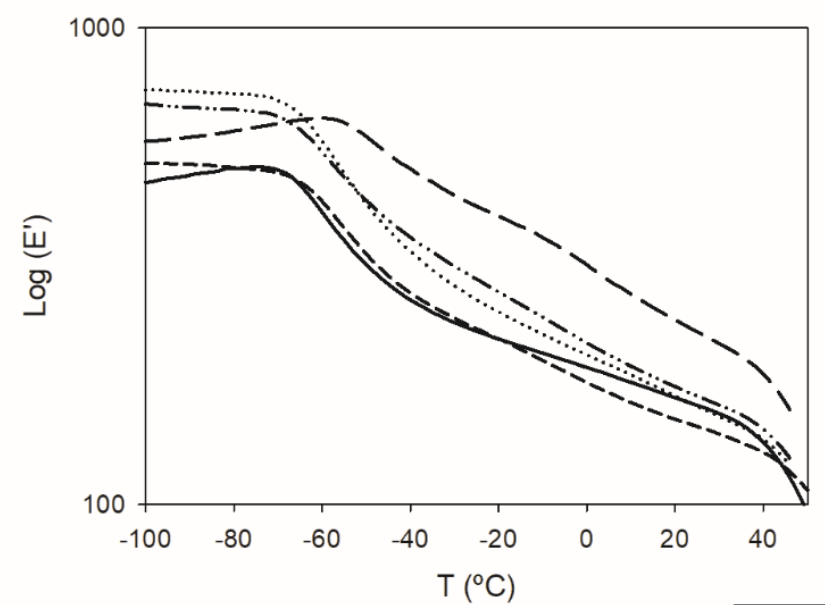

a)

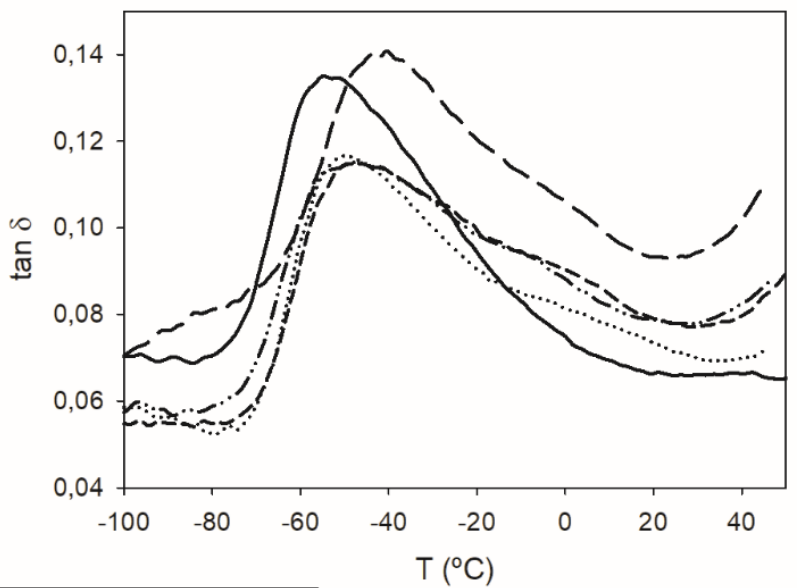

b)

$$
\begin{aligned}
& \begin{array}{ll}
\text { ……......... PCL } & \text { PCL/PEA }(5 \% \mathrm{w} / \mathrm{w})
\end{array} \\
& \begin{array}{ll}
----- & \text { PCL/PEA }(10 \% \mathrm{w} / \mathrm{w}) \\
-\cdot-\cdot-\cdots & \text { PCL/PEA }(15 \% \mathrm{w} / \mathrm{w}) \\
----- & \text { PCL/PEA }(20 \% \mathrm{w} / \mathrm{w})
\end{array} \\
& \text { - - - PCL/PEA }(20 \% \mathrm{w} / \mathrm{w})
\end{aligned}
$$

Figure 7. DMTA traces of the scaffolds: (A) Log (E') vs T, and (B) $\tan \delta v s \mathrm{~T}$.

In the E' profile (Figure 5(A)) it is possible to distinguish two regions: the glassy region, from -100 ${ }^{\circ} \mathrm{C}$ to $\mathrm{ca}$. $-60{ }^{\circ} \mathrm{C}$, in which the materials behave as stiff materials, and the glass transition zone, in which a decrease in the E' values is observed. In the case of the scaffolds analysed in the current work, the decrease in the E' values did not occur abruptly, but ranged from $-60{ }^{\circ} \mathrm{C}$ to $40{ }^{\circ} \mathrm{C}$. This result could be related with the crystalline regions (Table 4). At $c a .40{ }^{\circ} \mathrm{C}$ a sudden decrease in the E' occurred, which can be attributed to the beginning of the melting of the scaffolds. Regarding the $\tan \delta$ profiles (Figure 5(B)), in the case of the scaffold solely composed by PCL, a well-defined peak was obtained. In turn, the scaffolds containing PEA presented a broader $\tan \delta$ peak. This result can be ascribed to the high crystallinity (high $X_{\mathrm{c}}$ ) presented by these scaffolds. For higher crystalline structures, the amorphous domains have more difficulty in starting their motions at the 
same temperature, due to their entrapment within the crystalline domains, which results in broader $\tan \delta$ peaks. Nevertheless, and despite the broadness, only one peak is observed in the $\tan \delta$ curves, indicating that both components in the scaffold are compatible. Table 5 summarizes the values of E' at $37^{\circ} \mathrm{C}$ and also the $T_{\mathrm{g}}$ values for the scaffolds. The choice of the temperature to determine the $\mathrm{E}^{\prime}$ value is related to the fact that the scaffolds will be used for tissue engineering purposes.

Table 5. Values of E' and $T_{\mathrm{g}}$ for the scaffolds, determined by DMTA.

\begin{tabular}{ccc}
\hline Scaffold material & $\left.\mathbf{E}^{\prime}\left(\mathbf{3 7}^{\mathbf{0}} \mathbf{C}\right) \mathbf{( M P a}\right)$ & $\mathbf{T}_{\mathbf{g}}\left({ }^{\mathbf{0}} \mathbf{C}\right)$ \\
\hline PCL & 143 & -55 \\
PCL/PEA (5\% w/w) & 143 & -50 \\
PCL/PEA (10\% w/w) & 133 & -48 \\
PCL/PEA (15\% w/w) & 151 & -48 \\
PCL/PEA (20\% w/w) & 199 & -40 \\
\hline
\end{tabular}

The results show a significant increase in the E' value when the PEA is in weight percentages of $15 \%$ and $20 \%$, suggesting that the PEA has an important role in enhancing the mechanical properties of the scaffolds. In what respects the $T_{\mathrm{g}}$, an increase in its value is observed when the amount of PEA increases, and its value is in between the values of $T_{\mathrm{g}}$ of both components ( $T_{\mathrm{g} \text { (PEA, }}$ DSC) $\sim 2^{\circ} \mathrm{C}$ ). This result can be attributed to the increase in the percentage of crystallinity of the scaffolds, as observed in the DSC analysis, due to a more effective interaction between PCL and PEA (H-bonds $\mathrm{NH}_{\text {amide }} \cdots \mathrm{O}={ }_{\text {ester }}$ ). An increase in crystallinity lowers the mobility of the polymer chains, leading to an increase in the $T_{\mathrm{g}}$ value [44].

\section{Nanoindentation tests}

In the current research, nanoindentation tests were considered to analyse the potential effect of PEA on the surface properties of the scaffolds. Such testing method improves the force, displacement and spatial resolutions in comparison to conventional indentation techniques [45].

Nanoindentation is normally employed to map the surface mechanical properties and to evaluate those of microstructural features within bulk materials, bridging the gap between atomic force microscopy and macroscale mechanical testing.

Figure 8 reports the results obtained from nanoindentation measurements on the fibres of PCL and PCL/PEA scaffolds in terms of hardness as function of the applied load. 


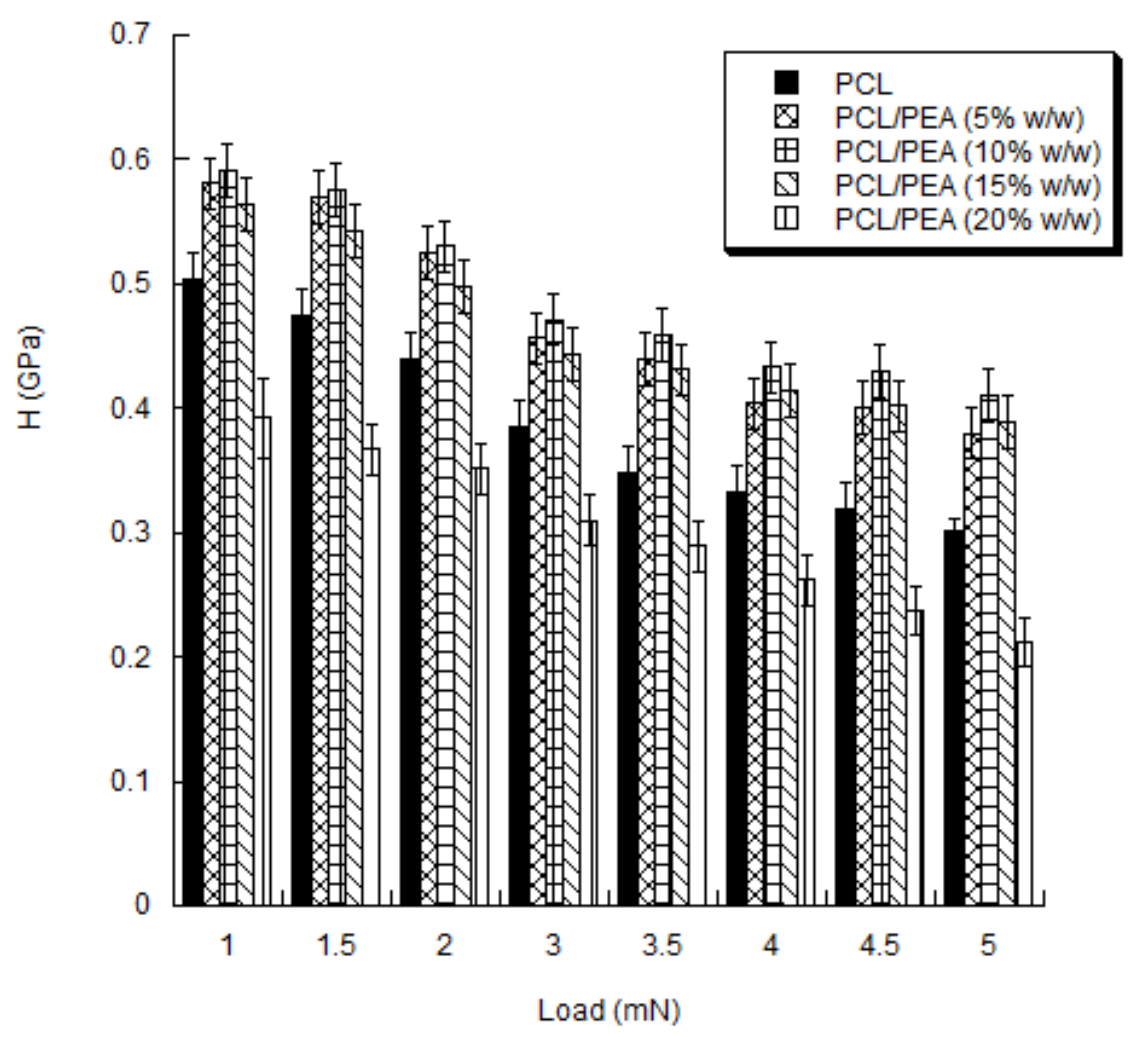

Figure 8. Results obtained from nanoindentation tests on the fibres of PCL and PCL/PEA scaffolds. Hardness as a function of the applied load $(1-5 \mathrm{mN})$. Data are reported as mean value and error bar represents the standard deviation. Statistical analysis was performed using ANOVA followed by Bonferroni post-hoc tests $(\mathrm{p}<0.05)$.

In particular, measurements on the fibres of PCL scaffolds provided hardness values spanning from $0.50 \pm 0.02 \mathrm{GPa}$ to $0.29 \pm 0.01 \mathrm{GPa}$ in the investigated load range. These values were lower than those obtained for the fibres of PCL/PEA ( $5 \% \mathrm{w} / \mathrm{w}$ ) (from $0.58 \pm 0.02 \mathrm{GPa}$ to $0.38 \pm 0.02 \mathrm{GPa}$ ), PCL/PEA $(10 \% \mathrm{w} / \mathrm{w}$ ) (from $0.60 \pm 0.02 \mathrm{GPa}$ to $0.41 \pm 0.02 \mathrm{GPa}$ ), PCL/PEA (15\% w/w) (from $0.56 \pm 0.02 \mathrm{GPa}$ to $0.39 \pm 0.02 \mathrm{GPa}$ ) scaffolds. Conversely, the lowest hardness values were achieved for PCL/PEA ( $20 \% \mathrm{w} / \mathrm{w}$ ) scaffolds (from $0.39 \pm 0.03 \mathrm{GPa}$ to $0.21 \pm 0.02 \mathrm{GPa}$ ). The observed differences were statistically significant. However, among PCL/PEA ( $5 \% \mathrm{w} / \mathrm{w})$, PCL/PEA ( $10 \% \mathrm{w} / \mathrm{w})$ and PCL/PEA $(15 \% \mathrm{w} / \mathrm{w})$ scaffolds there were no significant differences in terms of hardness. The values of hardness are related to polymer chain flexibility and, hence, to chemical and physical entanglements. Generally, the density of entanglements among the molecular chains provides a contribution to the rigidity of amorphous region of the polymers, representing a topological restriction of molecular motion [46]. Thus, nanoindentation behaviour is determined by molecular chains. Accordingly, if compared to PCL, the higher values of hardness achieved for the fibres of PCL/PEA (5\% w/w), PCL/PEA (10\% w/w) and PCL/PEA (15\% w/w) scaffolds may be probably 
ascribed to an increase in the density of physical entanglements formed as a consequence of PCL/PEA blending process during scaffold manufacturing, which should reduce the mobility and flexibility of molecular chains, and the surface should become harder [38]. It is also apparent that beyond a threshold concentration value for PEA $(15 \% \mathrm{w} / \mathrm{w})$ the blending process during scaffold manufacturing does not continue to play an effective role in increasing the hardness values. Whilst this appears to contradict our theory of a crystallinity-driven mechanical response of PCL/PEA scaffolds under dynamic conditions, it is worth noting that hardness data is normally collected from very small areas on the surface of printed filaments. These probed areas are likely to be heterogeneous in terms of amorphous and crystalline regions thus providing results that may not be representative of the macro-mechanical properties of the material.

\section{Compression tests}

Results from compression analyses evidenced the influence of PEA on the mechanical behaviour of the PCL scaffolds. The stress-strain curves (Figure 9) obtained for all tested scaffolds were consistent with those already reported for 3D printed PCL structures [34,47]. Values of compressive modulus and maximum stress are reported in Table 6.

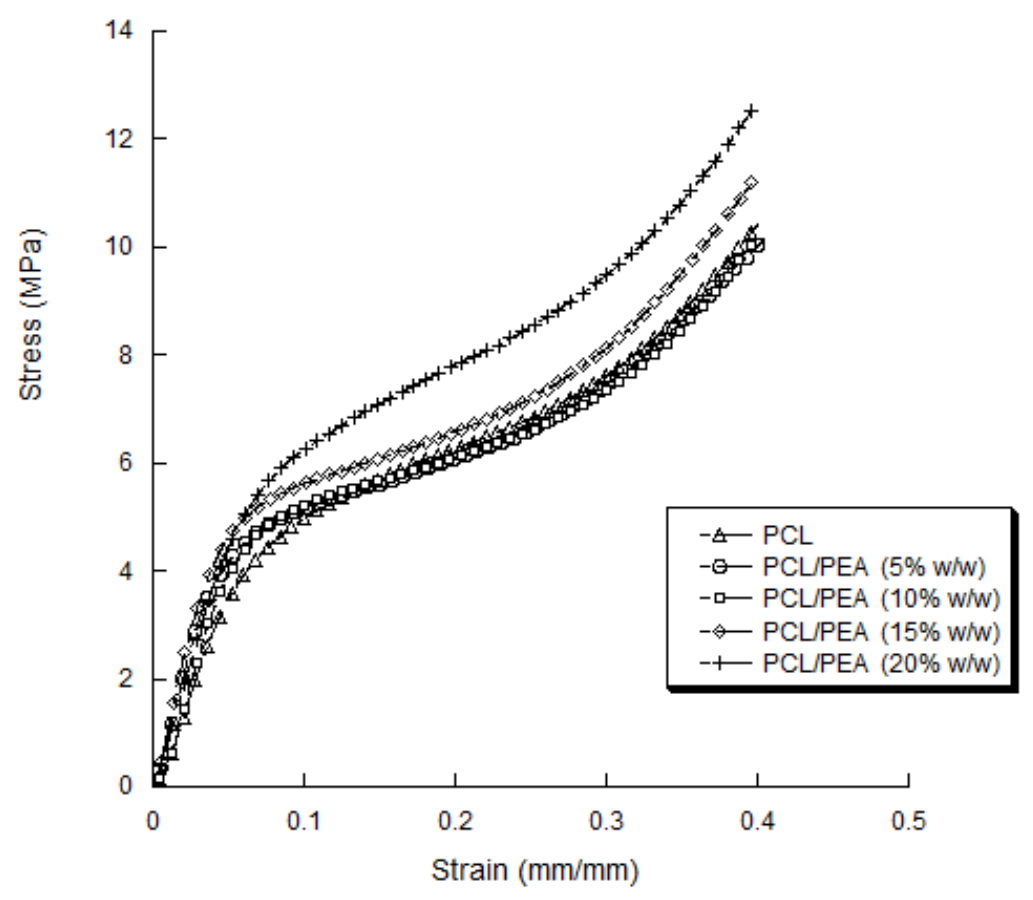

Figure 9. Typical stress-strain curves obtained from compression tests on 3D PCL and PEA/PEA scaffolds with $0 / 90^{\circ}$ lay-down pattern and a filament distance of $750 \mu \mathrm{m}$, tested at a rate of 1 $\mathrm{mm} / \mathrm{min}$ up to a strain of $0.4 \mathrm{~mm} / \mathrm{mm}$. 
Table 6. Effect of PEA on the compressive mechanical properties of PCL scaffolds. Modulus and maximum stress reported as mean value \pm standard deviation. Statistical analysis was performed using ANOVA followed by Bonferroni post-hoc tests ( $\mathrm{p}<0.05)$.

\begin{tabular}{llll}
\hline \multicolumn{2}{l}{ Scaffold material } & $\begin{array}{l}\text { Compressive Modulus } \\
\text { E (MPa) }\end{array}$ & $\begin{array}{l}\text { Maximum Stress } \\
\boldsymbol{\sigma}_{\max }(\mathbf{M P a})\end{array}$ \\
\hline PCL & & $87.0 \pm 5.7$ & $10.3 \pm 0.4$ \\
PCL/PEA & $5 \% \mathrm{w} / \mathrm{w}$ & $90.1 \pm 6.1$ & $10.2 \pm 0.5$ \\
PCL/PEA & $10 \% \mathrm{w} / \mathrm{w}$ & $93.0 \pm 6.6$ & $10.1 \pm 0.6$ \\
PCL/PEA & $15 \% \mathrm{w} / \mathrm{w}$ & $119.4 \pm 6.5$ & $11.4 \pm 0.3$ \\
PCL/PEA & $20 \% \mathrm{w} / \mathrm{w}$ & $138.9 \pm 7.2$ & $12.6 \pm 0.4$ \\
\hline
\end{tabular}

The values of compressive modulus and maximum stress for PCL scaffolds were $87.0 \pm 5.7 \mathrm{MPa}$ and $10.3 \pm 0.4 \mathrm{MPa}$, respectively (Table 6 ). In the weight percentage of $5 \%$ and $10 \%$, the presence of PEA did not significantly alter the values of compressive modulus and maximum stress (90.1 \pm 6.1 MPa and 10.2 $\pm 0.5 \mathrm{MPa}$ for PCL/PEA (5\% w/w), $93.0 \pm 6.6 \mathrm{MPa}$ and $10.1 \pm 0.6 \mathrm{MPa}$ for PCL/PEA (10\% w/w)) (Table 6). However, by further increasing the content of PEA to 15\% and 20 $\%$, the values of compressive modulus increased to $119.4 \pm 6.5 \mathrm{MPa}$ and $138.9 \pm 7.2 \mathrm{MPa}$, respectively. The same trend was observed in terms of maximum stress, particularly for scaffolds with $15 \%(w / w)$ and $20 \%(w / w)$ of PEA (Table 6$)$. In terms of compressive modulus and maximum stress, the observed differences between 3D PCL/PEA (15\% w/w) structures and PCL/PEA (20\% $\mathrm{w} / \mathrm{w})$ scaffolds were statistically significant $(\mathrm{p}<0.05)$. Even though nanoindentation measurements showed a significant increase of hardness for PCL/PEA (5\% w/w), PCL/PEA (10\% w/w) and PCL/PEA (15\% w/w) fibers if compared to PCL ones, from a macro-mechanical point of view compression tests evidenced a significant increase of modulus and maximum stress only for PCL/PEA (15\% w/w) and PCL/PEA (20\% w/w).

These results are in line with the DMTA analyses (Table 5) and further support the idea that the enhanced mechanical response of PCL/PEA scaffolds can be ascribed to a higher Xc (\%) as shown in Table 4.

\subsection{Water contact angle measurements}

Wettability and hydrophilicity of the fibres of PCL and PCL/PEA scaffolds were analysed using water contact angle measurements (Table 7). 
Table 7. Water contact angle reported as mean value \pm standard deviation for the fibres of PCL and PCL/PEA scaffolds. Statistical analysis was performed using ANOVA followed by Bonferroni post-hoc tests $(\mathrm{p}<0.05)$.

\begin{tabular}{lc}
\hline Scaffold & Water contact angle $\left(^{\circ}\right)$ \\
\hline PCL & $88.2 \pm 6.0$ \\
PCL/PEA $(5 \% \mathrm{w} / \mathrm{w})$ & $75.3 \pm 5.4$ \\
PCL/PEA $(10 \% \mathrm{w} / \mathrm{w})$ & $62.8 \pm 5.3$ \\
PCL/PEA $(15 \% \mathrm{w} / \mathrm{w})$ & $62.1 \pm 6.1$ \\
PCL/PEA $(20 \% \mathrm{w} / \mathrm{w})$ & $61.7 \pm 5.8$ \\
\hline
\end{tabular}

The values of the water contact angle achieved for the fibres of PCL/PEA structures were lower than the PCL ones $\left(88.2 \pm 6.0^{\circ}\right)$, spanning from to $75.3 \pm 5.4^{\circ}$ to $61.7 \pm 5.8^{\circ}$. As reported in the literature, PCL is a hydrophobic polymer and the obtained values of water contact angle (88.2 \pm $6.0^{\circ}$ ) were also influenced by the additive manufacturing technique (i.e., injection/extrusion based method) employed to fabricate the 3D scaffolds which affects the surface topography.

Significant differences were observed in the values of water contact angle between PCL structures and PCL/PEA scaffolds ( $\mathrm{p}<0.05)$. With regard to PCL/PEA scaffolds, PCL/PEA (5\% w/w) showed values of water contact angle which were significantly higher than those obtained for the other compositions, whereas no significant differences were found among the structures by increasing the content of PEA from a weight percentage of $10 \%$ to $20 \%$. It is worth noting that the increase of hydrophilicity of the scaffolds using PEA has a crucial role in the cellular adhesion and proliferation.

\subsection{Biological analysis}

In vitro biological tests were carried out to evaluate the influence of PEA on the biological behaviour of hMSCs. Figure 10 reports the results obtained from the Alamar Blue assay. 


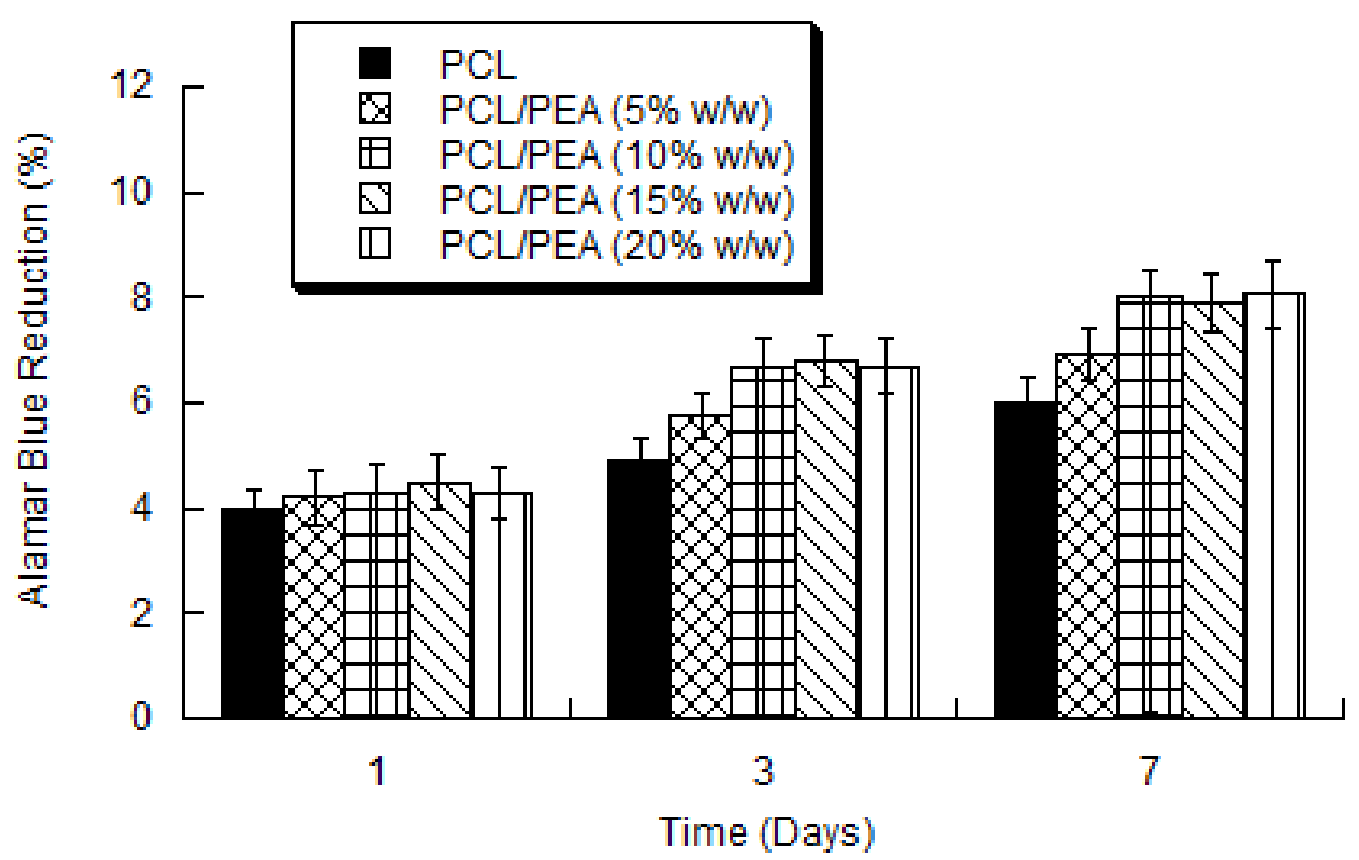

Figure 10. Percentage of Alamar Blue reduction as a function of time for PCL and PCL/PEA scaffolds. Data are reported as mean value and error bar represents the standard deviation. Statistical analysis was performed using ANOVA followed by Bonferroni post-hoc tests $(\mathrm{p}<0.05)$.

The Alamar Blue assay is based on a redox reaction which occurs in the mitochondria of the cells. The coloured product is transported out of the cell and is measured spectrophotometrically. The number of viable cells correlates with the magnitude of dye reduction and is expressed as a percentage of Alamar Blue reduction. A significant increase of Alamar Blue reduction indicates that hMSCs could survive and proliferate throughout the scaffolds. Accordingly, a higher reduction rate suggests a higher number of viable cells [38]. Our results show that, even though there were no differences between PCL scaffolds and PCL/PEA structures at day 1, the presence of PEA significantly improved cell viability/proliferation at 3 and 7 days $(p<0.05)$. With regard to PCL/PEA structures, at 3 and 7 days PCL/PEA (5\% w/w) scaffolds showed values of percentage of reduction of Alamar Blue which were significantly lower than those found for the other compositions $(\mathrm{p}<0.05)$. Moreover, at 3 and 7 days it was not possible to detect significant differences in terms of cell viability/proliferation among the PCL/PEA scaffolds structures by increasing the content of PEA from a weight percentage of $10 \%$ to $20 \%$.

To provide a further insight about the effect of PEA on cell morphology, confocal laser scanning microscopy (CLSM) was performed. As an example, the results obtained at the end of 3 days of incubation are reported in Figure 11. 

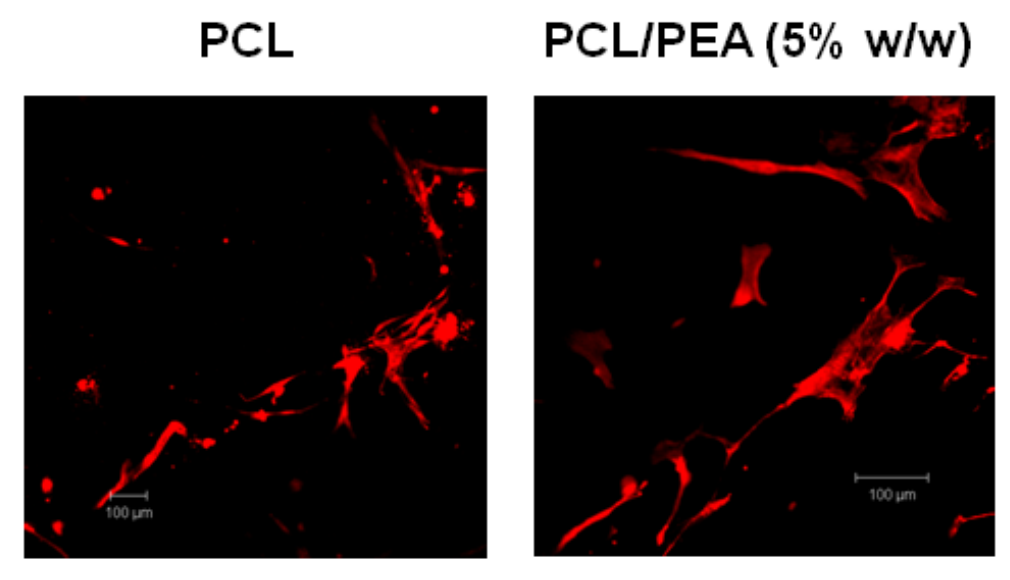

PCL/PEA $(10 \% \mathrm{w} / \mathrm{w})$
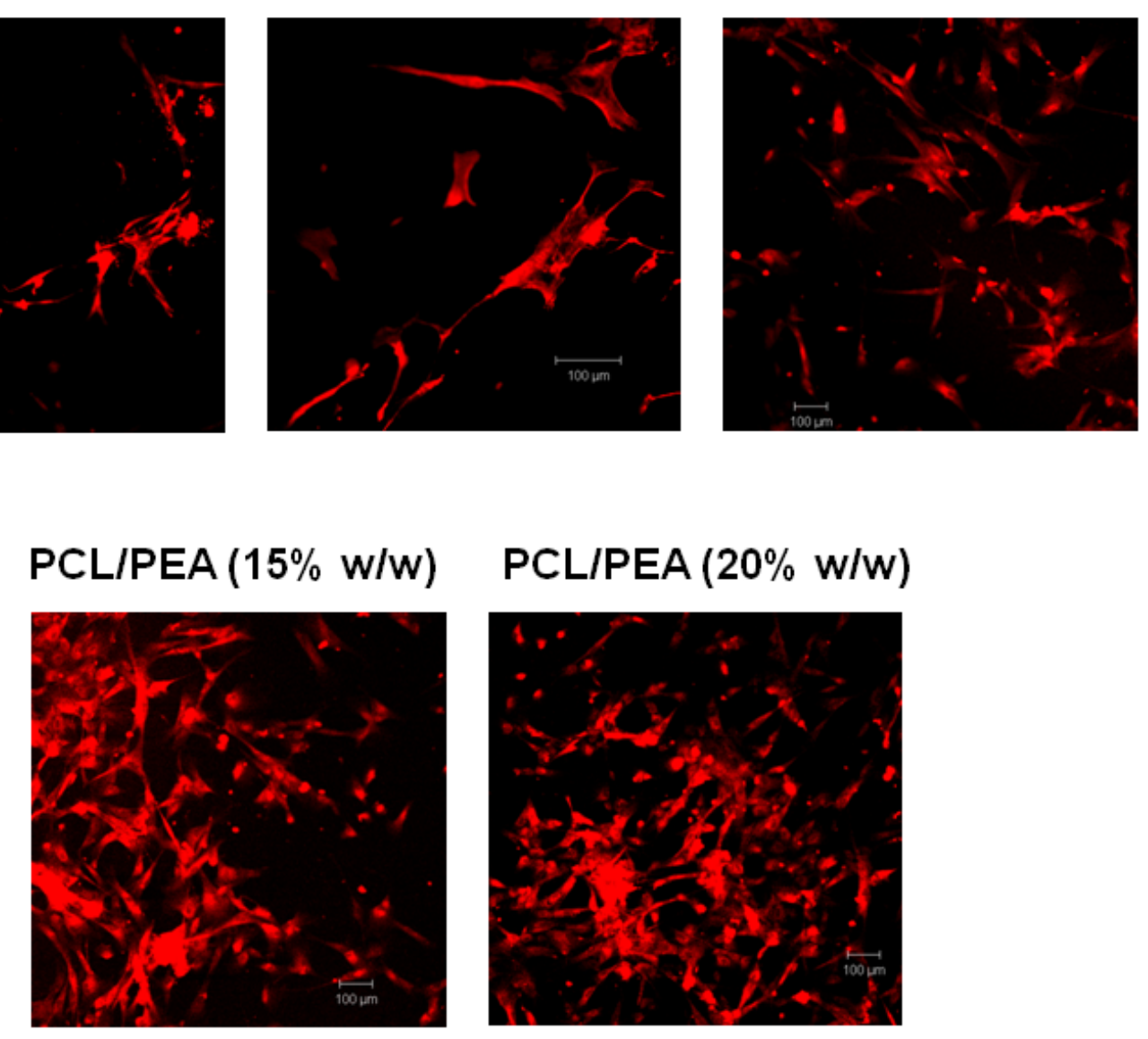

\section{PCL/PEA $(20 \% \mathrm{w} / \mathrm{w})$}

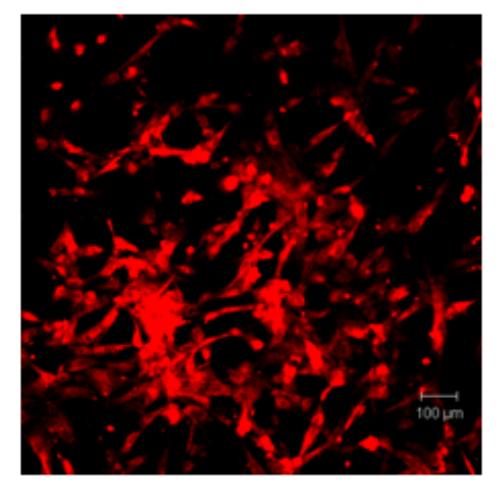

Figure 11. Typical results from CLSM analysis on PCL and PCL/PEA scaffolds at day 3. Images of rhodamine phalloidin-stained cells/actin cytoskeleton (red).

It is worth noting that cell morphology was influenced by the presence of PEA. Accordingly, with regard to PCL/PEA scaffolds, better cell spreading together with a much higher and homogeneous number of cells was well evident in comparison to PCL structures.

Cell adhesion and spreading were additionally analysed based on the determination of the shape factor using CLSM images. In Figure 12 typical values of the shape factor are reported (mean value \pm standard deviation) at 1,3 and 7 days after cell seeding. The cell shape factor significantly decreased over time for all kinds of cell-scaffold constructs. Even though at day 1 similar values were obtained for all the cell-scaffold constructs, at 3 and 7 days the highest shape factor was achieved for PCL scaffolds. Furthermore, at 3 and 7 days the values of the shape factor obtained for PCL/PEA (5\% w/w) structures were significantly higher than those found for the other compositions of PCL/PEA scaffolds. With regard to PCL/PEA (10\% w/w), PCL/PEA (15\% w/w) and PCL/PEA (20\% w/w), the observed differences were not statistically significant. Since the more elongated is the cell, the lower is the cell shape factor, a reduction in the shape factor should 
lead to better adhesion and spreading $[1,34,39]$. Therefore, the results obtained from the Alamar Blue assay and water contact angle measurements were in agreement with CLSM/shape factor analysis. These findings confirm the potential of PEA to promote cell adhesion, spreading and proliferation in additive manufactured PCL-based scaffolds through a dual mechanism of increased hydrophilicity and mechanical stiffness. Our results are in agreement with previous studies in which the ability of hMSCs to adhere and spread is strongly enhanced by stiffer substrates [48]. However, a more detailed study on the effect of substrate stiffness and surface topography of printed constructs will be required to fully understand the physicochemical mechanisms regulating hMSC function and growth.

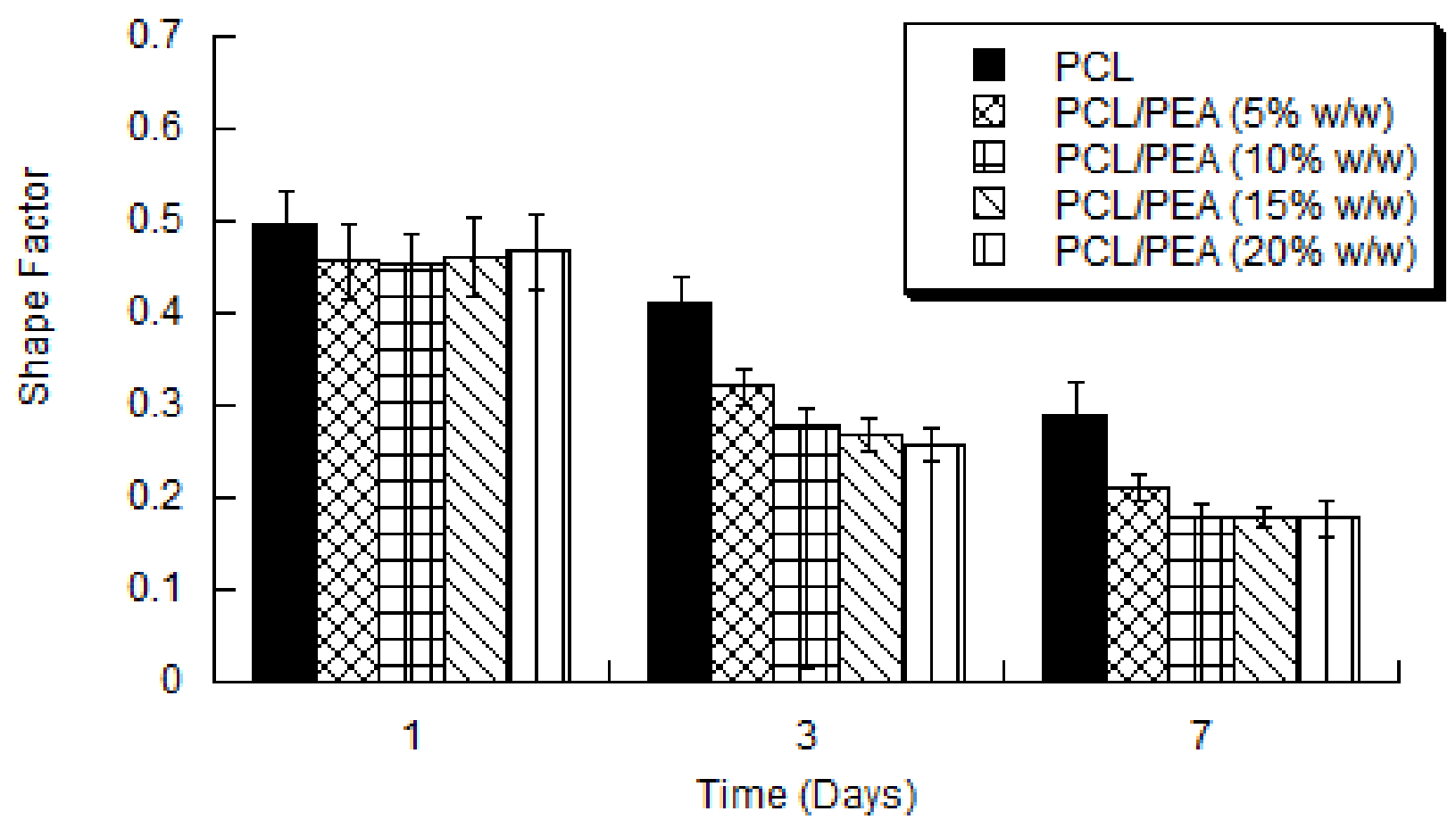

Figure 12. Typical values of shape factor obtained from CLSM images of hMSCs on PCL and PCL/PEA scaffolds. Data are reported as mean value and error bar represents the standard deviation. Statistical analysis was performed using ANOVA followed by Bonferroni post-hoc tests $(\mathrm{p}<0.05)$.

\section{Conclusions}

In the current study, a successful strategy to afford 3D scaffolds using miscible blends of PCL and PEA was reported. The synthesis of PEA with a proper chemical structure was critical to obtain miscible blends which can be used for additive manufacturing processes. A first analysis of the influence of PEA on the structural and functional features of 3D additive manufactured PCL scaffolds was carried out. The addition of PEA to PCL resulted in scaffolds with higher 
hydrophilicity, improved cell adhesion and proliferation. DMTA tests revealed an increased mechanical performance of 3D printed scaffolds with the addition of PEA up to a percentage of $20 \% \mathrm{w} / \mathrm{w}$. Moreover, a decrease of hardness was observed beyond a threshold concentration of PEA as the lowest values were obtained for PCL/PEA (20\% w/w) scaffolds, whereas compression tests demonstrated a significant increase of modulus and maximum stress only for PCL/PEA (15\% w/w) and PCL/PEA (20\% w/w). Our data is particularly relevant for the field of Bioprinting where a new window of opportunities can now be explored through the generation of PCL/PEA scaffolds with enhanced biomechanical performance and maintaining the easy processability typical of PCL material.

\section{References}

[1] M. Domingos, A. Gloria, J. Coelho, P. Bartolo, J. Ciurana, Three-dimensional printed bone scaffolds: The role of nano/micro-hydroxyapatite particles on the adhesion and differentiation of human mesenchymal stem cells, Proc. Inst. Mech. Eng. Part H J. Eng. Med. 231 (2017) 555-564. doi:10.1177/0954411916680236.

[2] J.A. Inzana, D. Olvera, S.M. Fuller, J.P. Kelly, O.A. Graeve, E.M. Schwarz, S.L. Kates, H.A. Awad, 3D printing of composite calcium phosphate and collagen scaffolds for bone regeneration, Biomaterials. 35 (2014) 4026-4034. doi:10.1016/j.biomaterials.2014.01.064.

[3] A.D. Olubamiji, Z. Izadifar, J.L. Si, D.M.L. Cooper, B.F. Eames, D.X.B. Chen, Modulating mechanical behaviour of 3D-printed cartilage-mimetic PCL scaffolds: Influence of molecular weight and pore geometry, Biofabrication. 8 (2016). doi:10.1088/1758-5090/8/2/025020.

[4] S.C. Cox, J.A. Thornby, G.J. Gibbons, M.A. Williams, K.K. Mallick, 3D printing of porous hydroxyapatite scaffolds intended for use in bone tissue engineering applications, Mater. Sci. Eng. C. 47 (2015) 237-247. doi:10.1016/j.msec.2014.11.024.

[5] H. Bae, H. Chu, F. Edalat, J.M. Cha, S. Sant, A. Kashyap, A.F. Ahari, C.H. Kwon, J.W. Nichol, S. Manoucheri, B. Zamanian, Y. Wang, A. Khademhosseini, Development of functional biomaterials with micro- and nanoscale technologies for tissue engineering and drug delivery applications, J. Tissue Eng. Regen. Med. 8 (2014) 1-14. doi:10.1002/term.1494.

[6] H. Sun, F. Zhu, Q. Hu, P.H. Krebsbach, Controlling stem cell-mediated bone regeneration through tailored mechanical properties of collagen scaffolds, Biomaterials. 35 (2014) 11761184. doi:10.1016/j.biomaterials.2013.10.054.

[7] A.R. Costa-Pinto, R.L. Reis, N.M. Neves, Scaffolds Based Bone Tissue Engineering: The Role of Chitosan, Tissue Eng. Part B Rev. 17 (2011) 331-347. doi:10.1089/ten.teb.2010.0704.

[8] L. Shor, S. Güçeri, R. Chang, J. Gordon, Q. Kang, L. Hartsock, Y. An, W. Sun, Precision extruding deposition (PED) fabrication of polycaprolactone (PCL) scaffolds for bone tissue engineering, Biofabrication. 1 (2009). doi:10.1088/1758-5082/1/1/015003.

[9] M.D. Schofer, P.P. Roessler, J. Schaefer, C. Theisen, S. Schlimme, J.T. Heverhagen, M. Voelker, R. Dersch, S. Agarwal, S. Fuchs-Winkelmann, J.R.J. Paletta, Electrospun plla nanofiber scaffolds and their use in combination with bmp-2 for reconstruction of bone defects, PLoS One. 6 (2011). doi:10.1371/journal.pone.0025462.

[10] H.J. Kim, J.H. Lee, G. Il Im, Chondrogenesis using mesenchymal stem cells and PCL scaffolds, J. Biomed. Mater. Res. - Part A. 92 (2010) 659-666. doi:10.1002/jbm.a.32414.

[11] L. Ghasemi-Mobarakeh, M.P. Prabhakaran, M. Morshed, M.H. Nasr-Esfahani, S. Ramakrishna, Bio-functionalized PCL nanofibrous scaffolds for nerve tissue engineering, 
Mater. Sci. Eng. C. 30 (2010) 1129-1136. doi:10.1016/j.msec.2010.06.004.

[12] B. Rai, S.H. Teoh, D.W. Hutmacher, T. Cao, K.H. Ho, Novel PCL-based honeycomb scaffolds as drug delivery systems for rhBMP-2, Biomaterials. 26 (2005) 3739-3748. doi:10.1016/j.biomaterials.2004.09.052.

[13] T. Patrício, M. Domingos, A. Gloria, U. D’ Amora, J.F. Coelho, P.J. Bártolo, Fabrication and characterisation of PCL and PCL/PLA scaffolds for tissue engineering, Rapid Prototyp. J. 20 (2014) 145-156. doi:10.1108/RPJ-04-2012-0037.

[14] N.P. Rijal, U. Adhikari, S. Khanal, D. Pai, J. Sankar, N. Bhattarai, Magnesium oxide-poly( $\varepsilon-$ caprolactone)-chitosan-based composite nanofiber for tissue engineering applications, Mater. Sci. Eng. B. 228 (2018) 18-27. doi:10.1016/J.MSEB.2017.11.006.

[15] W. Kosorn, M. Sakulsumbat, P. Uppanan, P. Kaewkong, S. Chantaweroad, J. Jitsaard, K. Sitthiseripratip, W. Janvikul, PCL/PHBV blended three dimensional scaffolds fabricated by fused deposition modeling and responses of chondrocytes to the scaffolds, J. Biomed. Mater. Res. - Part B Appl. Biomater. 105 (2017) 1141-1150. doi:10.1002/jbm.b.33658.

[16] M.A. Woodruff, D.W. Hutmacher, The return of a forgotten polymer - Polycaprolactone in the 21st century, Prog. Polym. Sci. 35 (2010) 1217-1256. doi:10.1016/j.progpolymsci.2010.04.002.

[17] A.C. Fonseca, M.H. Gil, P.N. Simões, Biodegradable poly(ester amide)s - A remarkable opportunity for the biomedical area: Review on the synthesis, characterization and applications, Prog. Polym. Sci. 39 (2014) 1291-1311. doi:10.1016/j.progpolymsci.2013.11.007.

[18] K. Ghosal, M.S. Latha, S. Thomas, Poly(ester amides) (PEAs) - Scaffold for tissue engineering applications, Eur. Polym. J. 60 (2014) 58-68. doi:10.1016/j.eurpolymj.2014.08.006.

[19] A.C. Fonseca, J.F.J. Coelho, J.F.A. Valente, T.R. Correia, I.J. Correia, M.H. Gil, P.N. Simões, Poly(ester amide)s based on (L)-lactic acid oligomers and $\alpha$-amino acids: Influence of the $\alpha$-amino acid side chain in the poly(ester amide)s properties, J. Biomater. Sci. Polym. Ed. 24 (2013) 1391-1409. doi:10.1080/09205063.2012.762293.

[20] A.C. Fonseca, A.C. Serra, J.F.J. Coelho, M.H. Gil, P.N. Simões, Novel poly(ester amide)s from glycine and L-lactic acid by an easy and cost-effective synthesis, Polym. Int. 62 (2013) 736-743. doi:10.1002/pi.4356.

[21] D.K. Knight, E.R. Gillies, K. Mequanint, Biomimetic l-aspartic acid-derived functional poly(ester amide)s for vascular tissue engineering, Acta Biomater. 10 (2014) 3484-3496. doi:10.1016/j.actbio.2014.04.014.

[22] Y. Xue, T. Yatsenko, A. Patel, D.B. Stolz, J.A. Phillippi, V. Sant, S. Sant, PEGylated poly(ester amide) elastomer scaffolds for soft tissue engineering, Polym. Adv. Technol. 28 (2017) 1097-1106. doi:10.1002/pat.4002.

[23] Y. Ohya, H. Matsunami, T. Ouchi, Cell growth on the porous sponges prepared from poly(depsipeptide-co-lactide) having various functional groups, J. Biomater. Sci. Polym. Ed. 15 (2004) 111-123. doi:10.1163/156856204322752264.

[24] G.C. Engelmayr, M. Cheng, C.J. Bettinger, J.T. Borenstein, R. Langer, L.E. Freed, Accordion-like honeycombs for tissue engineering of cardiac anisotropy, Nat. Mater. 7 (2008) 1003-1010. doi:10.1038/nmat2316.

[25] S.K. Murase, L.J. Del Valle, S. Kobauri, R. Katsarava, J. Puiggalí, Electrospun fibrous mats from a l-phenylalanine based poly(ester amide): Drug delivery and accelerated degradation by loading enzymes, Polym. Degrad. Stab. 119 (2015) 275-287. doi:10.1016/j.polymdegradstab.2015.05.018.

[26] E. Armelin, N. Paracuellos, A. Rodríguez-Galán, J. Puiggalí, Study on the degradability of poly(ester amide)s derived from the $\alpha$-amino acids glycine, and l-alanine containing a variable amide/ester ratio, Polymer (Guildf). 42 (2001) 7923-7932. doi:10.1016/S00323861(01)00315-9. 
[27] N. Paredes, A. Rodríguez-Galán, J. Puiggalí, Synthesis and characterization of a family of biodegradable poly(ester amide)s derived from glycine, J. Polym. Sci. Part A Polym. Chem. 36 (1998) 1271-1282. doi:10.1002/(SICI)1099-0518(199806)36:8<1271::AIDPOLA10>3.0.CO;2-3.

[28] G. Caetano, R. Violante, A.B. Sant'Ana, A.B. Murashima, M. Domingos, A. Gibson, P. Bártolo, M.A. Frade, Cellularized versus decellularized scaffolds for bone regeneration, Mater. Lett. 182 (2016) 318-322. doi:10.1016/j.matlet.2016.05.152.

[29] M. Domingos, F. Chiellini, A. Gloria, L. Ambrosio, P. Bartolo, E. Chiellini, Effect of process parameters on the morphological and mechanical properties of 3D Bioextruded poly(ecaprolactone) scaffolds, Rapid Prototyp. J. 18 (2012) 56-67. doi:10.1108/13552541211193502.

[30] D. Ronca, F. Langella, M. Chierchia, U. D’Amora, T. Russo, M. Domingos, A. Gloria, P. Bartolo, L. Ambrosio, Bone Tissue Engineering: 3D PCL-based Nanocomposite Scaffolds with Tailored Properties, in: Procedia CIRP, 2016: pp. 51-54. doi:10.1016/j.procir.2015.07.028.

[31] J. Ferreira, A. Gloria, S. Cometa, J.F.J. Coelho, M. Domingos, Effect of in vitro enzymatic degradation on 3D printed poly(epsilon-caprolactone) scaffolds: morphological, chemical and mechanical properties, J. Appl. Biomater. Funct. Mater. 15 (2017) E185-E195. doi:10.5301/jabfm.5000363.

[32] V. Crescenzi, G. Manzini, G. Calzolari, C. Borri, Thermodynamics of fusion of poly- $\beta$ propiolactone and poly- $\epsilon$-caprolactone. comparative analysis of the melting of aliphatic polylactone and polyester chains, Eur. Polym. J. 8 (1972) 449-463. doi:10.1016/00143057(72)90109-7.

[33] W.C. Oliver, G.M. Pharr, Measurement of hardness and elastic modulus by instrumented indentation: Advances in understanding and refinements to methodology, J. Mater. Res. 19 (2004) 3-20. doi:10.1557/jmr.2004.19.1.3.

[34] M. Domingos, F. Intranuovo, T. Russo, R. De Santis, A. Gloria, L. Ambrosio, J. Ciurana, P. Bartolo, The first systematic analysis of 3D rapid prototyped poly(??- caprolactone) scaffolds manufactured through BioCell printing: The effect of pore size and geometry on compressive mechanical behaviour and in vitro hMSC viability, Biofabrication. 5 (2013). doi:10.1088/1758-5082/5/4/045004.

[35] H. Chen, H. Cheng, Z. Jiang, D. Qin, Y. Yu, G. Tian, F. Lu, B. Fei, G. Wang, Contact Angles of Single Bamboo Fibers Measured in Different Environments and Compared with Other Plant Fibers and Bamboo Strips, BioResources. 8 (2013) 2827-2838. doi:10.15376/biores.8.2.2827-2838.

[36] X.-F. Wu, Y.A. Dzenis, Droplet on a fiber: geometrical shape and contact angle, Acta Mech. 185 (2006) 215-225. doi:10.1007/s00707-006-0349-0.

[37] M. Domingos, F. Intranuovo, T. Russo, R.D. Santis, A. Gloria, L. Ambrosio, J. Ciurana, P. Bartolo, The first systematic analysis of 3D rapid prototyped poly( $\varepsilon$ - caprolactone) scaffolds manufactured through BioCell printing: The effect of pore size and geometry on compressive mechanical behaviour and in vitro hMSC viability, Biofabrication. 5 (2013). doi:10.1088/1758-5082/5/4/045004.

[38] A. Gloria, F. Causa, T. Russo, E. Battista, R. Della Moglie, S. Zeppetelli, R. De Santis, P.A. Netti, L. Ambrosio, Three-Dimensional Poly(e-caprolactone) Bioactive Scaffolds with Controlled Structural and Surface Properties, Biomacromolecules. 13 (2012) 3510-3521. doi:10.1021/bm300818y.

[39] M. Domingos, F. Intranuovo, A. Gloria, R. Gristina, L. Ambrosio, P.J. Bártolo, P. Favia, Improved osteoblast cell affinity on plasma-modified 3-D extruded PCL scaffolds, Acta Biomater. 9 (2013). doi:10.1016/j.actbio.2012.12.031.

[40] J. Pagacz, A. Leszczyńska, M. Modesti, C. Boaretti, M. Roso, I. Malka, K. Pielichowski, Thermal decomposition studies of bio-resourced polyamides by thermogravimetry and 
evolved gas analysis, Thermochim. Acta. 612 (2015) 40-48.

doi:10.1016/J.TCA.2015.05.003.

[41] Y. Wang, M.A. Rodriguez-Perez, R.L. Reis, J.F. Mano, Thermal and Thermomechanical Behaviour of Polycaprolactone and Starch/Polycaprolactone Blends for Biomedical Applications, Macromol. Mater. Eng. 290 (2005) 792-801. doi:10.1002/mame.200500003.

[42] G. Ciardelli, V. Chiono, G. Vozzi, M. Pracella, A. Ahluwalia, N. Barbani, C. Cristallini, P. Giusti, Blends of poly-( $\varepsilon$-caprolactone) and polysaccharides in tissue engineering applications, Biomacromolecules. 6 (2005) 1961-1976. doi:10.1021/bm0500805.

[43] E. Can, G. Udenir, A.I. Kanneci, G. Kose, S. Bucak, Investigation of PLLA/PCL Blends and Paclitaxel Release Profiles, AAPS PharmSciTech. 12 (2011) 1442-1453. doi:10.1208/s12249-011-9714-y.

[44] Y. He, N. Asakawa, Y. Inoue, Studies on poly(?-caprolactone)/thiodiphenol blends: The specific interaction and the thermal and dynamic mechanical properties, J. Polym. Sci. Part B Polym. Phys. 38 (2000) 1848-1859. doi:10.1002/1099-0488(20000715)38:14<1848::AIDPOLB30>3.0.CO;2-F.

[45] D.M. Ebenstein, L.A. Pruitt, Nanoindentation of biological materials, Nano Today. 1 (2006) 26-33. doi:10.1016/S1748-0132(06)70077-9.

[46] J. Zhou, K. Komvopoulos, Surface and interface viscoelastic behaviors of thin polymer films investigated by nanoindentation, J. Appl. Phys. 100 (2006) 114329. doi:10.1063/1.2398797.

[47] Y. Rotbaum, C. Puiu, D. Rittel, M. Domingos, Quasi-static and dynamic in vitro mechanical response of 3D printed scaffolds with tailored pore size and architectures, Mater. Sci. Eng. C. 96 (2019) 176-182. doi:10.1016/J.MSEC.2018.11.019.

[48] M. Guvendiren, J.A. Burdick, Stiffening hydrogels to probe short- and long-term cellular responses to dynamic mechanics, Nat. Commun. 3 (2012) 792. doi:10.1038/ncomms1792.

\section{Supporting Information}

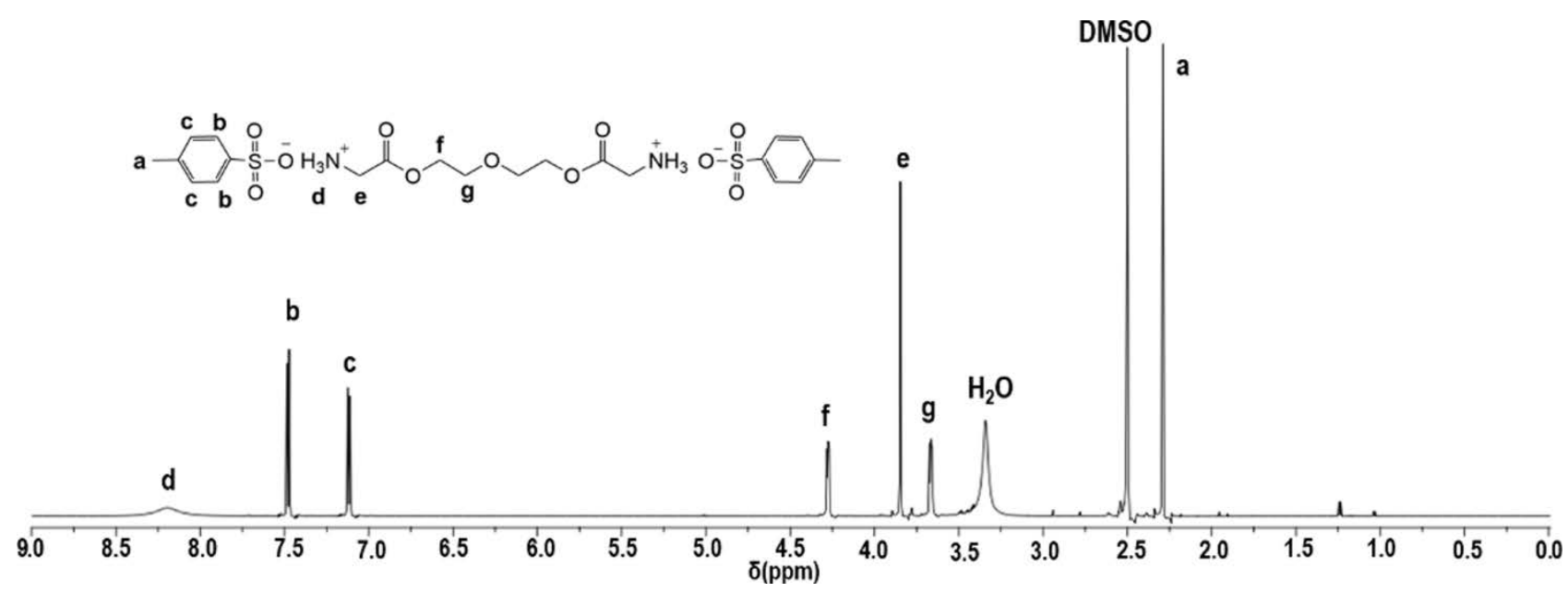

Figure S1. ${ }^{1} \mathrm{H}$ NMR spectrum of glycine based bis( $\alpha$-amino acid) ester, in DMSO- $d_{6}$. 


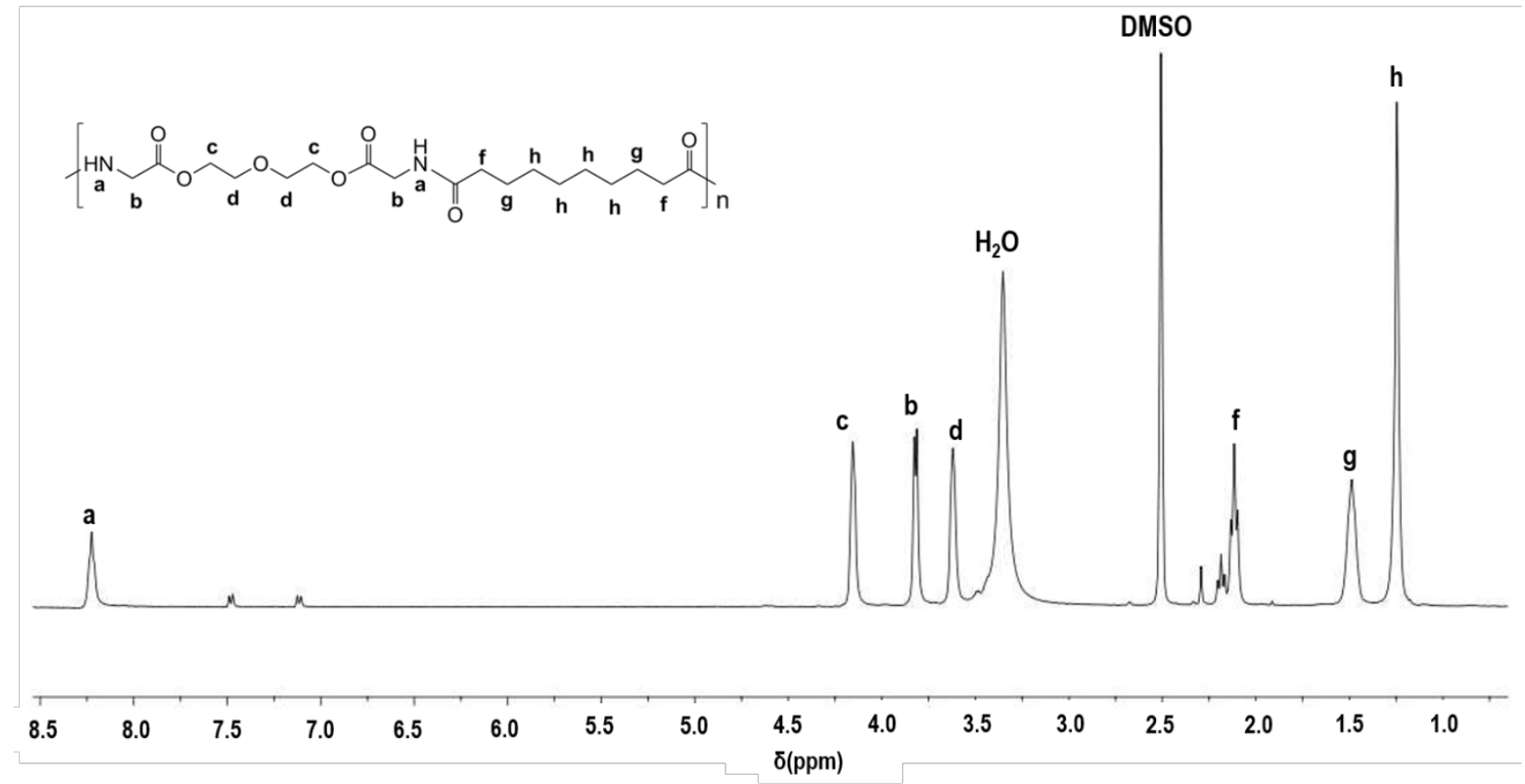

Figure S2. ${ }^{1} \mathrm{H}$ NMR spectrum of the PEA, in DMSO- $d_{6}$.

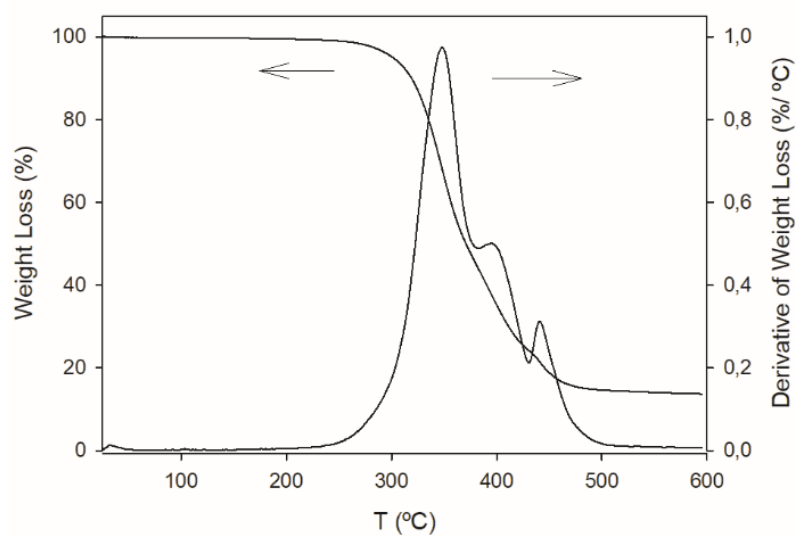

Figure S3. TG and DTG curves of the PEA.

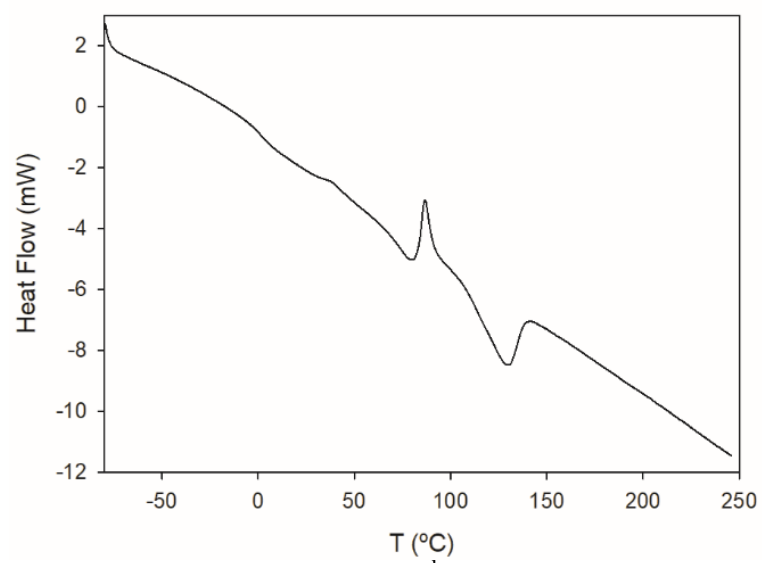

Figure S4. Heat flow curve ( $2^{\text {nd }}$ heating cycle) of the PEA. 


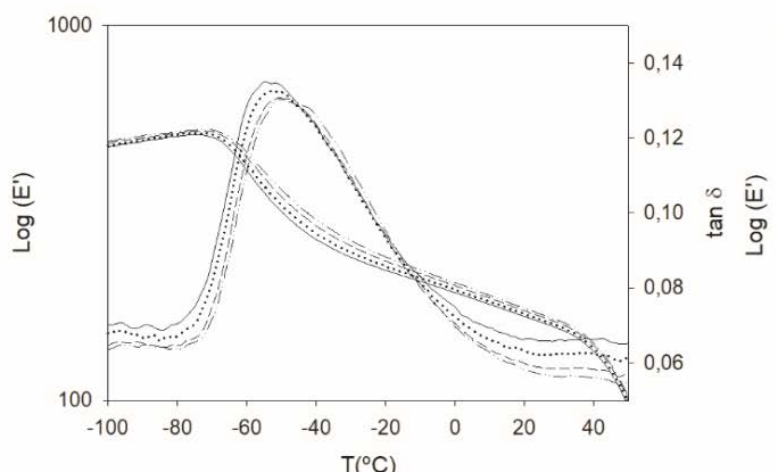

(A)

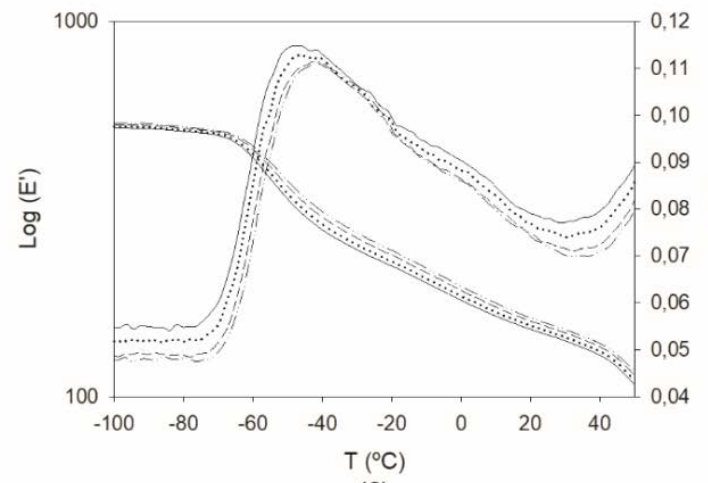

(C)

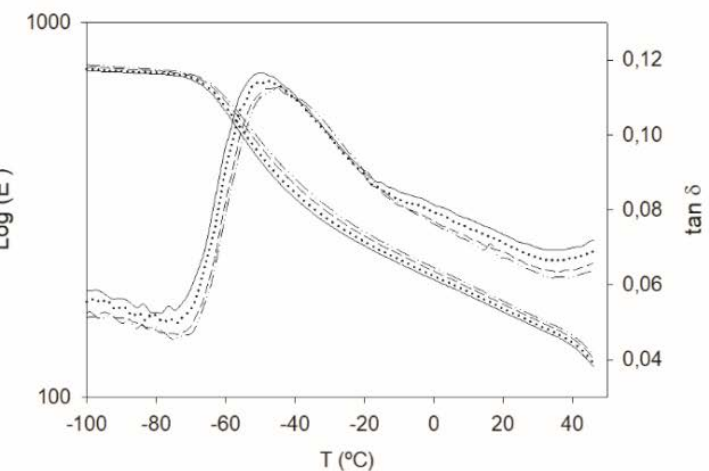

(B)

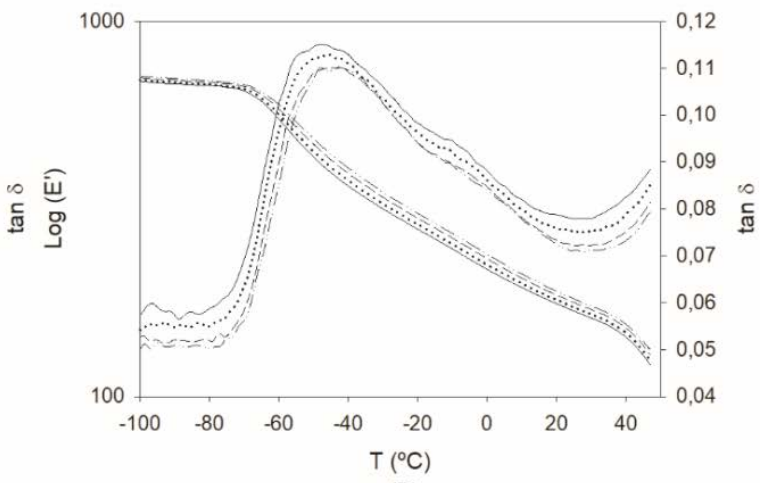

(D)

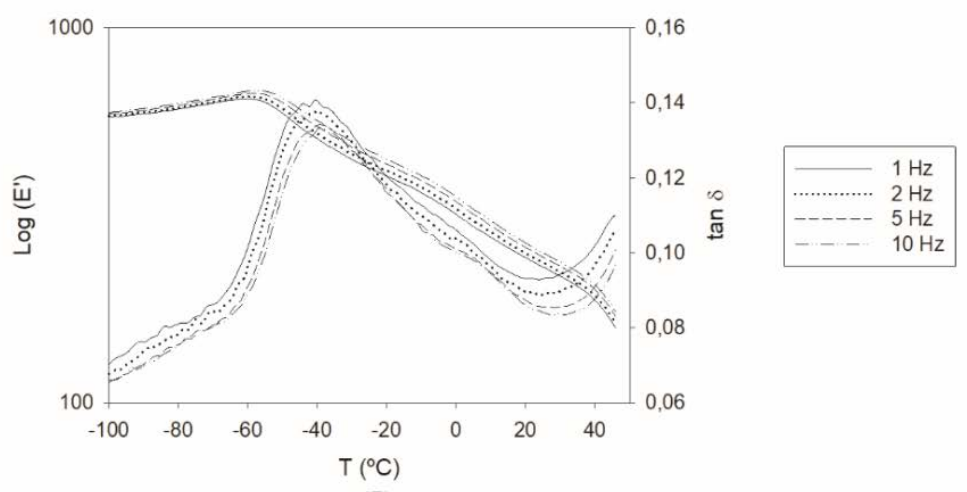

(E)

Figure S5. DMTA traces of the scaffolds, in multifrequency mode: (A) PCL; (B) PCL/PEA (5\% w/w); (C) PCL/PEA (10\% w/w); (D) PCL/PEA (15\% w/w); and (E) PCL/PEA (20\% w/w). 